\title{
Forestería comunitaria y desarrollo de instituciones locales: el caso de la Comunidad Agraria Teopisca
}

\section{Communitarian forestry and the development of local institutions: The case of Comunidad Agraria Teopisca}

\author{
Alma Rafaela Bojórquez -Vargas* \\ Eduardo Bello-Baltazar** \\ ConRado M árquez-Rosano*** \\ Luis Cayuela-Delgado**** \\ M anuel Parra-Vázquez**
}

\begin{abstract}
This study analyses, from an institutional point of view, the process of local management regarding forest usage in comunidad agraria Teopisca, Chiapas, M exico. We have found that, the agricultural workers have been successful in developing efficient local institutions to manage the usage and access to the forest. Similarly, we haveal so detected that those areas of the forest that are under more control and managed by the members of the community have more species whose wood has higher value in the marketplace.
\end{abstract}

Keywords collective action, communitarian forestry, territory appropriation, institutional viewpoint, common goods.

\section{Resumen}

En este estudio se analiza, a partir del enfoque institucional, el proceso de gestión local alrededor del aprovechamiento forestal en la Comunidad Agraria Teopisca, Chiapas (M éxico). Se encontró que los campesinos han logrado desarrollar instituciones locales eficientes para regular el uso y acceso de los recursos forestales. De igual forma, también se detectó que las áreas de bosque más controladas y atendidas por los integrantes de la comunidad son las que albergan más especies maderables con mayor valor en el mercado.

Palabras clave: acción colectiva, forestería comunitaria, apropiación del territorio, enfoque institucional, bienes comunes.

* Universidad Autónoma deSan Luis Potosí, M éxico. Correo-e: alma.bojorquez@ uaslp.mx.

** El Colegio de la Frontera Sur, M éxico. Correo-e: ebello@ecosur.mx y mparra@ ecosur.mx.

*** Universidad Autónoma Chapingo, M éxico. Correo-e: cmar_ros59@yahoo. com.mx.

**** Universidad de Granada. Correo-e: Icayuela@ugr.es. 


\section{Introducción}

En el mundo existen numerosos ejemplos de recursos naturales manejados adecuadamente por las comunidades locales que los poseen. Para lograrlo, muchas de ellas han desarrollado instituciones locales (sistema de reglas y acuerdos comunitarios) sólidas que les han permitido aprovechar el recurso sin atentar contra él. También permiten, entre sus miembros, una distribución equitativa de los beneficios y costos derivados de tales aprovechamientos.

H ace más de cuatro décadas que M ancur O Ison (1965) consideró que los integrantes de un grupo acceden a un bien colectivo disponible orientados principalmente por su interés individual, y que no invierten esfuerzos para mantenerlo a menos que el grupo sea pequeño y que se ejerza una coerción externa que los obligue a hacerlo. Después, Garret Hardin (1968) postuló que cuando un grupo de individuos comparte un recurso común tienden a aumentar su comportamiento egoísta (la no cooperación), provocando una sobreexplotación del recurso hasta que se deteriora o agota. A esto le denominó la tragedia de los comunes. Ante esta tragedia, $\mathrm{H}$ ardin sugirió la privatización o nacionalización de los recursos que se encuentren bajo propiedad común. Esta postura generó numerosas críticas en el sentido de que esta tragedia se verifica principalmente en casos donde los recursos son de acceso abierto, los cuales se caracterizan porque carecen de derechos de propiedad, por una indefinida exclusividad de usuarios en el acceso y por la desregulación. Feeny et al. (1990) relacionan estos recursos con los mares abiertos, con la atmósfera global y con las bandas de frecuencia radial.

En un sentido diferente, Elinor O strom (1990) sostiene que los poseedores de un recurso común tienen la capacidad de establecer instituciones por ellos mismos, para controlar las formas de uso y acceso de ese recurso o recursos que comparten colectivamente (recursos de uso común o Ruc). También dice que al establecer reglas y diseñar acuerdos entendidos y aceptados por todos, es posible fomentar estrategias de cooperación para mantener los recursos de uso común, ya sean agua, bosques, animales de caza o pesca, pastizales, etc., y lograr un aprovechamiento más eficiente de los mismos. Para analizar este tipo de instituciones, la autora propone utilizar el enfoque institucional (O strom, 1990). 
Para este enfoque, 0 strom identificó los siguientes principios de diseño $0^{1}$ que caracterizan a las instituciones locales exitosas en la gestión de recursos comunes: para empezar, los usuarios del recurso común deben mantener límites de sus recursos claramente definidos y límites en el número de usuarios que los aprovecharán. Distingue también que los usuarios diseñen un sistema de reglas coherentes entre actividades de extracción (sustracción) y de provisión, elaboradas colectivamente, e indica que estas reglas se vigilen en su cumplimiento y que, a su vez, se apliquen sanciones graduadas para castigar las faltas cometidas. Entre estos principios de diseño también señala que tales grupos tienen acceso a mecanismos para resolver sus conflictos, que el gobierno reconozca -al menos en un mínimo- los derechos a organizarse localmente y, por último, menciona que el desarrollo de normas y solución de conflictos se desarrollan en diferentes niveles anidados (Ostrom, 1990). A menor presencia de estos principios, se infiere que el desarrollo institucional es débil, o que puede fracasar. Sin embargo, si también se busca elucidar los procesos sociales que subyacen a las instituciones locales, es necesario explicar su desarrollo y contar con elementos para anticipar su devenir inmediato, lo cual constituye un referente importante para comparar con otras experiencias. Cabe señalar que además de los principios de diseño de este enfoque, este estudio considera muy relevante el análisis de la historia comunitaria, pues con ello se identifican y dimensionan causas y factores que originan la fortaleza de estas instituciones. Al reconocer lo anterior, en este trabajo se profundizó en el análisis del proceso histórico local relacionado con el acceso a la tierra y la lucha por el territorio.

Este estudio se lleva a cabo en una comunidad agraria de la región de Los Altos de Chiapas como un estudio de caso, donde se analizaron las experiencias de gestión para administrar los recursos forestales de propiedad común. Estas experiencias forman parte de un proceso de apropiación territorial en la comunidad, que con el tiempo da lugar al desarrollo de instituciones que regulan el uso y acceso a sus recursos forestales.

\section{Las instituciones y la apropiación territorial}

Actuar colectivamente (collective action) para lograr mayores beneficios de un recurso de uso comunitario permite que las de-

${ }^{1}$ Design Principles (O strom, 1990). 
cisiones estén sometidas a cumplir las reglas y acuerdos establecidos de manera participativa a lo largo del tiempo por quienes tienen derecho a su acceso. En este sentido, la finalidad de un sistema de reglas y acuerdos entre los actores locales es hacer viable el uso sostenido del recurso común a largo plazo. Al concepto que utilizamos en este enfoque se denomina instituciones de acción colectiva (O strom, 1990).

En relación con lo anterior, este proceso de conformación de reglas y acuerdos logrados por una acción colectiva es una de las dimensiones que Weber y Reveret (1993) identifican en un proceso de apropiación de los recursos naturales. Linck confirma esta relación y establece que el concepto de apropiación del territorio y sus recursos debe quedar asociado con las instituciones como una relación de fuerza y entendimiento colectivo, que usa un complejo de reglas para definir las modalidades de apropiación y especificar el territorio mismo, y menciona que "Las instituciones del territorio conforman así su principio organizador básico y, más que las fronteras en sí, definen lo que marca diferencia entre lo externo y lo propio" (Linck, 2006: 17).

A esta relación entre apropiación territorial e instituciones locales es lo que denominamos en este estudio proceso de gestión local de los recursos naturales. Al analizarlo, nos será de utilidad para explicar cómo un grupo social logra desarrollar instituciones locales sólidas para regular el aprovechamiento de sus recursos, en este caso, forestales.

Un aspecto esencial en los estudios sobre instituciones locales que regulan los recursos forestales es la recomendación de Gibson et al. (2000) sobre la necesidad de conocer la estabilidad o los cambios que sufre el recurso mismo. Aunque los cambios en la superficie forestal pueden responder a múltiples causas (Angelsen y Kaimowitz 1999), es importante analizar cómo las decisiones sociales pueden modificar el estado del recurso, ya sea para mejorarlo, deteriorarlo o que permanezca estable. Diversos estudios encuentran relación entre la presencia de instituciones locales y un menor deterioro del recurso (Cortina et al., 2005; Gibson et al., 2000; Bray et al., 2003; M erino, 2004). En este sentido, este trabajo consideró importante relacionar lo anterior y se elaboró un análisis geográfico de los cambios o la estabilidad de la superficie forestal.

¿Por qué relacionar este estudio con los recursos forestales? En M éxico, la preocupación por los bosques ha cobrado mayor interés en los últimos años porque se consideran "muy altos en biodiversidad a nivel mundial" (IBRD, 1995) y porque ocupan una 
amplia superficie en régimen de propiedad común. Los bosques y selvas ocupan $29 \%$ del territorio nacional y suman 56.8 millones de ha. Cerca de $80 \%$ de ellos pertenecen a aproximadamente nueve mil ejidos y comunidades. ${ }^{2}$ Con esto, M éxico es uno de los países en el mundo con mayor proporción del territorio forestal en régimen de propiedad común ${ }^{3}$ (M erino, 2004: 33).

Utilizando enfoque institucional o no, diferentes estudios han analizado la gestión de los recursos bajo regímenes de propiedad común, como sistemas de irrigación, pesquerías, tierras para pastoreo y bosques, y coinciden en la postura de que las instituciones creadas local mente para aprovechar estos recursos se suelen sostener mejor que otros regímenes de propiedad (Berkes, 1987; Bromley et al., 1992; N etting, 1993). En M éxico son notables las contribuciones de estudios de bosques regulados bajo instituciones comunitarias, principalmente en los estados de M ichoacán (Alcorn y Toledo, 1998; Klooster, 2002; M erino, 2004), Q uintana Roo (Bello, 2001; Bray y M erino, 2004; M erino, 2004), O axaca (Chapela, 1999; Garibay, 2002) y Chiapas (M árquez, 2005; Tejeda-C ruz, 2005).

El objetivo principal de esta investigación es encontrar los elementos importantes que caracterizan el proceso de gestión local de los recursos forestales en la comunidad. Para cubrir este objetivo se partió de los siguientes cuestionamientos: 1) ¿la comunidad cuenta con instituciones de acción colectiva para controlar sus recursos forestales?, 2) ¿cómo es el desempeño de tales instituciones?, 3) ¿qué eventos históricos contribuyeron a su

2 El marco legal reformado en 1992 (artículo 27 y Ley Agraria respectiva) reconoce tres formas de propiedad de tierras y aguas: pública, privada y social. Esta última corresponde a los núcleos agrarios: ejidos y comunidades agrarias. Sobre este tipo de propiedad M éxico ha experimentado una serie de circunstancias inusuales en el mundo, pues en la tercera década del siglo xx se da lugar a una reforma agraria que dota de tierras a campesinos (ejidos) y devuelve a indígenas los territorios que por tiempos inmemorables poseían (comunidades), entonces se reconoce la propiedad social de las tierras. Tierras de las que anteriormente se habían apropiado caciques y grandes latifundistas. Esta forma de propiedad social condujo a un sustancial control comunitario de los bosques mexicanos creando una estructura de política y gobierno local del territorio al proveer una relación estructurada entre comunidades locales y el gobierno mismo. "Relación que hasta hoy llega a ser un aspecto arraigado en la cultura rural de M éxico" (Bray et al., 2006: 473). El reconocimiento legal de los miembros ejidatarios o comuneros, así como el apoyo general de su propiedad y asuntos de gestión de sus recursos lo administra la Secretaría de la R eforma Agraria (SRA) y es legislado por la Ley Agraria. Estas autoridades han ejercido fuerte influencia legal y administrativa sobre la propiedad común, y en particular sobre los recursos forestales.

${ }_{3}^{3}$ M cKean (2000) se refiere a este régimen de propiedad como un arreglo de derecho de propiedad en el cual un grupo de usuarios de un recurso comparten tanto derechos como obligaciones respecto al recurso mismo. 
desarrollo?, 4) ¿cómo han influido los actores externos en las acciones de la comunidad sobre el recurso? y 5) ¿existe alguna relación entre la gestión local de la comunidad con el estado actual del recurso?

\section{Z ona de estudio}

Chiapas, localizado al extremo sur de M éxico en el límite con Guatemala, es uno de los siete estados mexicanos 4 con mayor cobertura forestal y todavía en 1994 contaba con 3'293,196 ha de bosques y selvas (SARH, 1994) que correspondían a $44.6 \%$ de su superficie, de la cual $55 \%$ se encuentra en manos de comunidades y ejidos (INEGI, 1993). Los procesos de deterioro de la cobertura forestal en $C$ hiapas se deben principalmente a incendios forestales (Semarnap, 1998), a la expansión de la ganadería extensiva y a la descontrolada extracción de madera (Villafuerte et al., 1997).

Una de las regiones en que C hiapas se divide es la montañosa de Los Altos que se ubica en la porción central del estado, es en esta región donde se localiza la comunidad sujeta a este estudio de caso denominada Comunidad Agraria Teopisca o Bienes Comunales de Teopisca ${ }^{5}$ (figura I). La región de Los Altos, que comprende 18 municipios, ocupa $21 \%$ de la superficie estatal y alberga 37\% $(420,164 \mathrm{ha})$ de sus bosques templados (1'117,248 ha) (Semarnap, 1998). Por este motivo se considera una zona prioritaria para la conservación. Además, se caracteriza por su numerosa población indígena de las etnias tzeltal y tzotzil, un alto índice de analfabetismo y por un muy al to grado de marginación social y económica (Coespo, 2000).

$\mathrm{H}$ istóricamente los campesinos de Los Altos han usado y transformado el suelo de manera continua para la producción de alimentos (Parra, 1989). A la par, el deterioro de los recursos forestales ha aumentado a causa de la explotación extensiva de los recursos naturales (González et al., 1997). Al respecto, para esta región se estimó una tasa anual de deforestación de $4.8 \%$ en el periodo de 1990 a 2000 (Cayuela et al., 2006b: 212); sin embar-

${ }^{4}$ Los otros estados son: Durango, Chihuahua, O axaca, M ichoacán, Guerrero y Jalisco, aunque también cuentan con recursos forestales considerables Q uintana Roo, Veracruz, Puebla y Campeche (Elementos para la Reforma de la Ley Forestal de 1992).

${ }^{5}$ Localmente y en el gobierno de Chiapas esta comunidad se conoce como Bienes Comunales de Teopisca, pero en el Censo Agropecuario 1991 del INEGI se enlista como Comunidad Agraria Teopisca. Es común que esta comunidad se confunda con el ejido Teopisca, pues habitan en el mismo pueblo, pero son distintos grupos agrarios. 


\section{Figura I}

\section{Localización Región Altos de Chiapas}

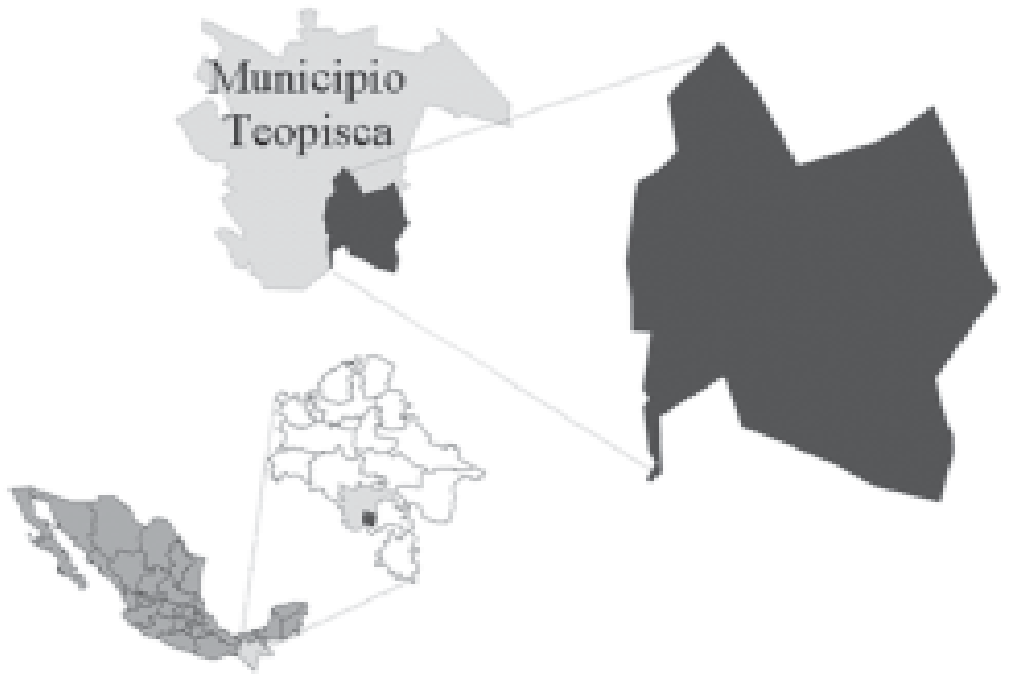

Fuente: Elaboración propia.

go, en la región aún se observan amplias áreas de cobertura forestal en diferentes estados de madurez (Pizano et al., 2002)

La Comunidad Agraria Teopisca pertenece al municipio del mismo nombre, en Chiapas, y se encuentra 1,800 msnm, con una superficie territorial de 3,015 ha y pertenece a la subcuenca hidrológica del río Aguacatenango, que a su vez se ubica dentro de la cuenca F del río Grijalva-La Concordia ${ }^{6}$. Su clima es predominantemente semicálido, subhúmedo, con una temperatura media anual de $18^{\circ} \mathrm{C}$. La comunidad se ubica junto a la cabecera municipal que cuenta con cerca de diez mil habitantes, se considera el segundo centro de población en la región después de la ciudad de San Cristóbal de Las Casas (INEGI, 2000), por lo que cuenta con carreteras pavimentadas en sus principales vías de acceso. Los propietarios de la localidad suman 178 comuneros, en su mayoría hombres que son jefes de familia y unas pocas mujeres viudas. Ellos recuerdan que sus antecesores hablaban en lengua tzeltal, pero ahora sólo se comunican en castellano. La gran mayoría practica la agricultura campesina y tienen como cultivos principales maíz y frijol. 
Los bosques de la comunidad se componen sobre todo de especies de pino y encino (Pinus y Quercus spp.), con pequeñas áreas de ciprés (Cupressus sp.). Las primeras ventas de madera se realizaron en pie $^{7}$ a mediados de 1980, sin embargo, desde 1996 se comercializa madera en rollo (fuste de árbol en trozas) bajo un programa de manejo con autorización oficial, aunque sólo duró dos años pues se suspendió en 1998 a causa de la sobreextracción anual que se programó en la deficiente planeación de un prestador de servicios forestales (PSF). En 2000 la comunidad obtuvo nuevamente la autorización oficial mediante un nuevo programa de manejo forestal rediseñado por un nuevo PSF. Ambos programas han seguido el método de desarrollo silvícola que se promovió en M éxico a comienzos de la década de los setenta (Torres-Rojo, 2005) y se caracteriza porque se aplican diversos tratamientos en un mismo predio, utilizando sobre todo el método de regeneración de árboles padre y otros, como cortas de liberación y aclareos.

\section{M etodología}

Este trabajo se abordó con un enfoque de las ciencias sociales como un estudio de caso, aplicando técnicas cualitativas y cuantitativas. Para obtener información histórica detallada de la comunidad se realizaron entrevistas abiertas y semiestructuradas a informantes clave, como comuneros de mayor edad y/o que hubieran ocupado cargos importantes en la comunidad en los rubros de datos generales de la comunidad, formas actuales de organización comunitaria y relación con las instituciones de gobierno respecto al recurso forestal. Con este paso se obtuvieron los datos que responden a la pregunta tres de las cinco expuestas anteriormente.

Esta información sirvió de base para diseñar un cuestionario estructurado que se aplicó a 64 comuneros $^{8}$ sobre los siguientes temas: reglas y acuerdos comunitarios sobre el acceso y uso de

${ }^{7} \mathrm{M}$ adera en pie es el término usado en forestería para referirse a la venta de árboles en pie donde sólo el comprador decide qué árbol se lleva y usa su propio equipo y personal externo. En este tipo de transacción no se emplea a la comunidad, sólo les paga a precios muy bajos.

${ }^{8}$ El tamaño de la muestra surgió primero de una prueba piloto, en la cual se le preguntó a 15 comuneros si identifican las distintas áreas forestales y los límites de la comunidad. El $60 \%$ respondió que identifican muy fácilmente todas las áreas y límites, mientras que $40 \%$ se compone de los que identifican casi todas las áreas, y de quienes identifican sólo algunas. Con estos porcentajes desarrollamos la fórmula: $n=N \quad p(1-p) /$ $(\mathrm{N}-1) \mathrm{B}^{2} / \mathrm{Za} / 2^{2}+\mathrm{p}(1-\mathrm{p})$. 
sus recursos forestales, formas de supervisión y de sanciones ante el incumplimiento de lo establecido, límites territoriales de la comunidad, identificación de las áreas de aprovechamiento maderable, la forma de organización en torno a las actividades forestales y, además, se pidió opinión sobre la rendición de cuentas y la participación en la toma de decisiones. Del mismo modo se cuestionó so bre el reparto de los beneficios obtenidos por la venta de madera y de la importancia económica de estos ingresos en relación con otras actividades.

Para estos cuestionarios se seleccionó a comuneros de distintos barrios, de diferentes edades y sexo tratando de representar la diversidad de posturas entre el total de ellos. Por otro lado, se llevaron a cabo entrevistas semiestructuradas al PSF y a dos funcionarios representantes de la federación en la región, como la Comisión $\mathrm{N}$ acional Forestal (Conafor) y la Secretaría de M edio Ambiente y Recursos $\mathrm{N}$ aturales (Semarnat). Esto con el fin de analizar la influencia de los actores desde diferentes escalas (M 0rán et al., 1998) y obtener datos sobre aspectos de asesoría técnica forestal, así como conocer la forma de participación de los agentes de gobierno en la comunidad.

Para tomar nota de las reglas formalizadas por escrito se tuvo acceso a un único libro de actas de reuniones de asamblea ordinarias y extraordinarias. El libro estaba en manos del comisariado ejidal, quien afirmó que es hasta los últimos años que se da formalidad por escrito a los acuerdos tomados en las reuniones, pues antes no se acostumbraba hacerlo, además de que pocos de los integrantes sabían leer y escribir.

Para conocer los espacios de comunicación y discusión sobre asuntos del bosque, se presenciaron seis reuniones ordinarias de asamblea general de la comunidad y 14 reuniones del Comité Forestal (de febrero a julio del 2005). D urante las estancias en la comunidad se hicieron recorridos en campo para conocer las actividades de aprovechamiento forestal, como marqueo de árboles, corta, derribe y arrastre de fustes, poda de especies reforestadas, chapeo de residuos y carga y cubicación de madera vendida. Se acompañó en la vigilancia del bosque y en el monitoreo

Donde: $\mathrm{n}=$ tamaño de la muestra; $\mathrm{N}=$ tamaño de la población (178); $\mathrm{p}=$ porcentaje que respondió que sí (.60); $\mathrm{B}=$ error muestral $(0.1) ; \mathrm{y} \mathrm{Za} / 2=1.96$ para un nivel de confianza de $95 \%$. El resultado nos señaló una n de 61 como mínimo tamaño de la muestra pero ya en el desarrollo de muestreo surgieron un total de 64 cuestionarios aplicados. 
de árboles con plaga. Además, se colaboró en la recolección de semillas de pino para la reproducción de plántulas.

Gracias a este acompañamiento en las actividades en el bosque, a las notas tomadas del libro de actas, a las visitas presenciales en reuniones de la asamblea y a los cuestionarios estructurados se obtuvo valiosa información para analizar los principios de diseño de E. O strom (1990) y con ello abordar las preguntas 1, 2 y 4. Cabe señalar que también, a lo largo del trabajo de campo, se obtuvieron importantes datos a partir de conversaciones informales con diferentes comuneros, sus esposas e hijos, con las autoridades locales, funcionarios del sector, técnicos forestales y avecindados del pueblo.

Para analizar los datos cuantitativos se utilizó el programa SPSS ${ }^{\circledR}$ versión 11 , cuyos resultados más relevantes fueron las frecuencias porcentuales; mientras que para analizar los datos cualitativos se elaboraron esquemas detallados que sirvieron para simplificar y ordenar la información obtenida, para ello se utilizó el programa M indM anager ® 2002.

Por último, para abordar la pregunta 5, se requirió indagar si hubo cambios de la superficie forestal a lo largo del tiempo. Para lograrlo se elaboró un análisis geográfico mediante dos imágenes de satélite: una del año 1990 y otra del 2000 procedentes de sensores remotos distintos (Landsat TM y ETM +, respectivamente). Como era necesario comparar estas imágenes entre sí, se tuvo que hacer la corrección geométrica, atmosférica y topográfica de las mismas, con el fin de que los resultados fueran consistentes en la serie. ${ }^{9}$

Con un GPS (Global Positioning Satellite) se tomaron coordenadas geográficas en diferentes puntos de la comunidad: 15 dentro de bosque con dosel y siete en áreas sin bosque. Con estos puntos se procedió a una clasificación supervisada utilizando un algoritmo basado en la teoría de la evidencia de Dempster-Shafer. Este es un método eficiente utilizado más recientemente en los análisis geográficos de vegetación, pues permite combinar la información disponible en las bandas espectrales del sensor con la información derivada del conocimiento experto (Cayuela et al., 2006a). El procesamiento de imágenes se realizó con el programa IDRISI 14.01 Kilimanjaro ${ }^{\circledR}$.

\footnotetext{
${ }^{9}$ Las correcciones geométricas incluyen cualquier cambio en la posición que ocupan los pixeles que forman la imagen, es decir, se corrigen sus coordenadas geográficas. En las correcciones radiométricas se pretendió modificar los niveles digitales de los pixeles de la imagen por efectos de la sombra, la atmósfera, etcétera (Chuvieco, 2002: 292).
} 


\section{Resultados y discusión}

En el primer apartado se describe el proceso histórico de apropiación del territorio que marcó los inicios de la gestión comunitaria. Después se aborda el análisis mediante los principios de diseño de O strom (1990) y finalmente se presenta el análisis de los cambios en la superficie forestal del área de estudio.

\subsection{El proceso de apropiación del territorio y los reaursos forestales}

Esta primera parte de resultados cobra mayor importancia para aquellos estudios que pretenden Ilevar análisis basados sólo en los principios de diseño, ya que en este caso la conformación de las instituciones locales en torno a los recursos forestales en la comunidad no surgieron por la simple preocupación de aprovechar eficientemente el recurso mismo, sino que deriva de un continuo proceso de apropiación del territorio, que comenzó con la lucha por la tierra y que a la postre originó capacidades de gestión colectiva. Se identificaron tres acontecimientos significativos de apropiación: 1) la lucha por el territorio, 2) las actividades de reforestación y 3) primeras comercializaciones de madera. Simultáneamente el proceso dio lugar a fortalecer las capacidades locales en el manejo forestal comunitario

\subsubsection{La lucha por el territorio}

La comunidad comienza su experiencia en 1969, cuando un grupo de campesinos sin tierra descubre que existen documentos ${ }^{10}$ que amparan la propiedad común y que permanecieron ocultos durante décadas. Para entonces, ese terreno ya estaba repartido entre pocos señores acaudalados de forma individual que vivían en el pueblo de Teopisca (identificados por ellos como los ricos), mientras que otra extensión de tierra estaba tomada por los vecinos del ejido Teopisca. Estos campesinos sin tierra, al convencerse de la validez oficial de los documentos y planos, acordaron organizarse para solicitar oficialmente la devolución del territorio como propiedad común. Como resultado, un grupo de 542

${ }^{10}$ Veintitrés fojas de documentos que amparan propiedad común, cinco planos que comprenden terrenos comunes ubicados al sur de la cabecera municipal y copia de escritura que acredita la compra-venta de una fracción de terreno, estos documentos datan de 1933. 
aspirantes a comuneros se organizaron y coordinaron acciones para tal gestión. Entonces surgió un conflicto por la propiedad de la tierra entre los ricos y los aspirantes a comuneros. Los primeros expresaron amenazas de muerte a los segundos para que desistieran la gestión de devolución de la propiedad. Esta lucha por la tierra se mantuvo a lo largo de seis años.

D urante ese tiempo, los aspirantes se reunían largas horas para diseñar diferentes estrategias que les permitiera lograr una gestión eficaz de la propiedad común. El objetivo era poseer tierra para cultivar y asegurar la provisión de alimentos, contar con un patrimonio para sus familias, y así dejar de pagar altos costos por alquilar tierras ajenas. Pero durante este mismo periodo, entre los aspirantes a comuneros también surgían conflictos internos. Al diferir con los acuerdos iniciales del grupo, una minoría se unió a los ricos llevando el conflicto a una mayor tensión. Los aspirantes eran cada vez menos en número e intensificaron estrategias, tanto para enfrentar las amenazas constantes del enemigo fortalecido como para optimizar la gestión de la tierra. Gracias a la valoración y apoyo de la Secretaría de la Reforma Agraria (SRA), el 24 de enero de $1973^{11}$ los aspirantes a comuneros lograron la dotación oficial definitiva de 3,128 ha en común, ${ }^{12}$ aunque aún faltaron muchos años más para que el conflicto lograra enfriarse.

Una larga lucha por la tierra enfrentando amenazas y conflictos requería de una intensa comunicación grupal, de ensayo y error en el diseño de estrategias y de acuerdos colectivos para lograr una gestión eficaz que los condujera a la posesión legal del territorio. En este estudio se reconoce esta experiencia colectiva como el inicio de un proceso paulatino de apropiación del territorio $y$, por ende, de sus recursos naturales. Al mismo tiempo representa la base de la experiencia organizativa y liderazgo local que da confianza grupal en la posibilidad de lograr objetivos organizadamente. Es decir, fortalece el capital social de grupo ya que éste "se basa en las relaciones sociales de las comunidades humanas que les permiten desarrollar conocimientos y visiones comunes, entendimiento mutuo, rendición de cuentas y confianza entre sus miembros, condiciones indispensables para la constitución y vigencia de cualquier acuerdo social" (V. O strom, 1997, citado por M erino, 2004: 129).

${ }^{11}$ De acuerdo con el documento de "Reconocimiento y Titulación de Bienes Comunales", por medio de Resolución Presidencial del 24 de enero de 1973 expedido por el Departamento de Asuntos Agrarios y Colonización del Gobierno Federal.

12 Tiempo después, con la pavimentación de las carreteras que cruzan Teopisca, éstas se convierten en caminos federales, lo que hace que la propiedad disminuya a 3,015 ha. 
Las relaciones sociales refuerzan la identidad y el reconocimiento de las personas; y ser reconocido garantiza el mantenimiento de ciertos recursos (Lin, 2001: 20). El ser identificado como comunero o comunera les garantizaba reconocimiento social, acceso a la tierra y fortaleza de grupo en actividades de gestión. En este caso los comuneros se distinguen en el pueblo por el grupo agrario al que pertenecen: comunero, ejidatario, vecino o particular.

\subsubsection{Las actividades de reforestación}

O tro suceso que afirmó la apropiación del territorio comenzó en 1982. En ese tiempo se implementaba una política federal de reforestación por medio de la SARH. La mayoría de los entonces comuneros fueron contratados con pago de jornales para reforestar aproximadamente 2,000 ha con plántulas de especies de coníferas. Después de esa reforestación, las siguientes las emprendieron ellos mismos con ayuda de la SARH sin esperar pago de jornales. Desde entonces, la reforestación es parte de las faenas colectivas, es decir, trabajos colectivos semejantes al tequio de las comunidades de 0 axaca. Estas actividades significan lo contrario de la extracción, es decir, se hacen para provisión, fomento y protección del bosque mediante reforestación, podas y aclareos anuales de los árboles, apertura y mantenimiento de brechas cortafuego, rondas de vigilancia, control de plagas, etc., y no son remuneradas, se consideran una contribución a la comunidad. Para los comuneros las actividades de reforestación fueron importantes para restaurar el territorio logrado. Ellos habían luchado por poseer un territorio, y después estaban dispuestos a trabajarlo y demostrar que tenía dueño.

Para Linck, la marca que deja el individuo en la producción del territorio se advierte en el trabajo ejercido en el mismo: "La apropiación del territorio y sus recursos siempre queda asociado con una relación de fuerza (un territorio se conquista y se defiende), con el establecimiento de al gún grado de exclusividad de uso" (2006: 17).

En este caso, las faenas de reforestación manifiestan un modo de apropiación porque representan simbólicamente rasgos de dominio del territorio y de exclusividad de derechos de quienes lo han producido (Weber y Reveret, 1993). De acuerdo con Gibson et al., "una comunidad invertirá mayores esfuerzos de organización cuando compartan el entendimiento de que los beneficios 
que resulten son dignos en relación con los costos de organizarse" (2000: 229). El logro de poseer el territorio y el esfuerzo de las faenas colectivas formaron las bases para que la comunidad valorara los bosques. A diferencia de las faenas colectivas, los trabajos de monte sí son remunerados y son todas aquellas actividades que se realizan para la extracción de madera comercial.

A lo largo de los años los comuneros han demostrado disponibilidad para realizar los trabajos de provisión en su territorio y principalmente en las áreas de bosque. La valoración económica que las comunidades asignan a los recursos forestales es una condicionante que determina la conservación o el deterioro de los mismos (M erino, 2004). En este caso, además del valor económico, los comuneros también le asignan un valor social, pues los recursos forestales están en un territorio del que lograron apropiarse, y los trabajos de reforestación simbolizan el resultado de los esfuerzos anuales que han invertido desde hace más de 20 años.

\subsubsection{Primeras comercializaciones de madera}

A mediados de los años ochenta los comuneros descubrieron que grandes extensiones de sus bosques de pino estaban infestadas de plaga (con el insecto descortezador Dendroctonus frontales). La SARH recomendó extraer los árboles plagados para comercializarlos como madera. Así la comunidad obtuvo pagos de derechos de monte ${ }^{13}$ al realizar las primeras ventas de madera en pie en 1987 y 1988 bajo la asesoría de la SARH. Esta coyuntura agregó el ementos para valorar aún más el bosque, pues los comuneros descubrieron el valor económico de sus recursos maderables en el mercado que antes desconocían. Con los ingresos obtenidos, los comuneros compraron una extensión de tierra de 332 ha de mayor productividad agrícola para el cultivo de maíz y frijol en el municipio vecino de Venustiano Carranza, ubicado a 20 km de la cabecera municipal de Teopisca. Esta adquisición de tierra fue dividida en parcelas de igual tamaño entre todos los comuneros, quienes uniformemente la destinaron para sembrar estos granos.

Esta reinversión reforzó sustancialmente la valoración del recurso forestal, en especial el bosque de coníferas, lo que signi-

\footnotetext{
${ }^{13}$ Los pagos por derechos de monte era la modalidad con la que las comunidades y ejidos cobraban por la venta de madera y los madereros industriales tenían derecho a explotar terrenos. Esta modalidad la acordó la Secretaría de la R eforma Agraria y sólo por este medio se pagaba la madera a las comunidades y ejidos (Chambille, 1983; M erino y Segura, 2002).
} 
ficó una fuente de ingresos para invertir en su cultivo principal: maíz y frijol. Por cerca de cinco años no se planeó aprovechar más madera porque precisamente en esta época (entre 1989 y 1994) el gobierno de Chiapas impuso una veda forestal en el estado. No hubo más venta de madera durante ese tiempo, pero sostenían su economía con el aumento en la producción de maíz y frijol en las tierras adquiridas. Fue hasta 1996, con el primer programa de manejo forestal, cuando continuaron las faenas anuales de reforestación, se practicaron faenas para podas anuales, aclareos, elaboración y mantenimiento de brechas para prevenir incendios, así como rondas de observación para control de plagas en pinares (actividades de provisión).

Actual mente la actividad principal de los comuneros sigue siendo el maíz y el frijol para consumo doméstico, aunque el sobrante de maíz se comercializa, pero el aprovechamiento forestal les permite contar con un ingreso anual repartido equitativamente por la venta de madera en rollo. La comunidad decide a quién vender el producto maderable de acuerdo con el mejor postor, pues tiene la gran ventaja de que se localiza muy cerca de la ciudad de San C ristóbal de Las Casas. Su ubicación en medio de carreteras pavimentadas facilita el transporte de la madera, lo que permite superar los precios estándares de madera en rollo en la región. En general los precios de la madera en Chiapas se encuentran más bajos que en el resto del país, por ejemplo, en M ichoacán en el año 2000 el precio de la madera de coníferas era de 700 pesos (64 dólares) ${ }^{14} \mathrm{~m}^{3}$ (M erino, 2004), mientras que en ese mismo año la Comunidad Teopisca vendió a 350 pesos (32 dólares) el $\mathrm{m}^{3}$ de madera en rollo. Cada año han ido mejorando el precio, en 2005 vendieron a poco más de 600 pesos (55 dólares) el $\mathrm{m}^{3}$ de madera primaria (rollos anchos) y a 170 pesos (15 dólares) de madera secundaria (rollos pequeños no más angostos de 25 de diámetro). Aun así, la comunidad mantiene el precio de madera primaria más alto en la región.

El volumen programado de extracción de madera para el año 2005 fue de 1,726 m³ , el más bajo en los 10 años que establece el programa de manejo (en promedio, está planeada una extracción anual de 4,000 $\mathrm{m}^{3}$ ). De este volumen se comercializaron $1,200 \mathrm{~m}^{3}$ de madera primaria y el resto de madera secundaria. En ese año los comuneros sólo se repartieron los ingresos de la

${ }^{14}$ Dólares estadounidenses que en M éxico, para las fechas de este estudio, el tipo de cambio fluctuaba en un promedio de 11 pesos por dólar. 
venta de madera primaria, quedando a cada uno cerca de 4,000 pesos (364 dólares), mientras que los ingresos por madera secundaria se destinaron a la remuneración de los trabajos de monte y los gastos de operación. Aunque ese año hubo menos extracción, y por tanto recibieron ingresos menores, la mayoría asegura que es de mucha utilidad para solventar los gastos cotidianos durante el año.

Para $67 \%$ de los comuneros la actividad forestal representa entre la segunda y tercera fuente de ingresos. El reparto anual de los ingresos por venta de madera es una fuente de financiamiento, que para algunos significa una solución a los gastos en los insumos agrícolas, mientras que para otros es una oportunidad para mejorar las condiciones de la vivienda, así como gastos en salud y educación de sus familias, además de que anualmente genera cerca de 30 empleos internos durante la cosecha de madera. ${ }^{15}$ Cada jornal se paga entre 60 y 70 pesos diarios, un poco más alto que el estándar en la región (6.36 dólares).

Desde las primeras extracciones de madera en pie los comuneros desconocían las actividades de forestería, pero observaron cada paso de las labores de monte que ejercían los trabajadores del comprador (el maderero). Después, los comuneros empezaron a practicar estos trabajos durante el primer aprovechamiento con un programa de manejo forestal de extracción maderable (entre 1996 y 1998), y con la capacitación ${ }^{16}$ del PSP y la entonces Secretaría de M edio Ambiente, Recursos N aturales y Pesca (Semarnap) poco a poco se volvieron hábiles para hacerlo por ellos mismos. A partir de entonces los comuneros condicionan a los madereros para que, en lugar de sus empleados, sean ellos mismos quienes desempeñen los trabajos de extracción.

Dependiendo de la situación y de lo que más convenga a los comuneros, se acuerda que algunos trabajos los pague la comunidad y otros el maderero, quien no siempre es el mismo, sino que varía según se acerque a las condiciones que la comunidad establece como precio, modalidades de pago y cuestiones técnicas de extracción en cada año de aprovechamiento.

${ }^{15}$ Empleos temporales que van desde marqueo de árboles, troza, chapeo, arrastre de fustes, hacinamiento de trozas, carga y documentación de madera cargada (cubicación), además de los cargos del Comité Forestal y del Vivero mientras ejerzan sus responsabilidades.

${ }^{16}$ En los trabajos de monte como: marqueo de árboles, uso de motosierra, técnicas de derribe, arrastre y hacinamiento de fustes en el patio de carga, corte de trozas de rollo, carga y cubicación de madera. 
Casi todos los trabajos de monte los realizan los propios comuneros, los cuales ocupan un promedio de 30 personas, mientras que para las faenas colectivas los 178 comuneros y comuneras tienen la misma responsabilidad de ejercerlas. Cuando no se puede acudir a ellas, se permite enviar a algún familiar o pagar a quien lo supla (cuadro 1).

Los comuneros consultan constantemente al PSP y a los funcionarios de Conafor sobre los aspectos y técnicas de forestería como: precios de madera en el mercado, técnicas de manejo, documentación oficial que se debe presentar y aspectos fitosanitarios del bosque. De acuerdo con esta observación, en este estudio se identifica un marcado interés de los comuneros por encontrar las condiciones ideales para manejar sus recursos forestales maderables. El interés por aprender los trabajos de monte, los cálculos de madera (cubicación) y la documentación necesaria surgió de los propios comuneros, lo que evidencia otra muestra de apropiación territorial.

El marcado interés por desarrollar capacidades para manejar adecuadamente sus bosques se explica porque con ello mantienen un control directo sobre el recurso, lo que les permite garantizar mayores beneficios económicos anualmente y oportunidades de empleo local. Esto se aprecia en otras comunidades que administran sus bosques, como en el caso de la comunidad $\mathrm{X}$ hazil en Q uintana Roo (Bello, 2001), San Pedro el Alto en Oaxaca (Garibay, 2002) y San Juan N uevo M ichoacán (Bonfil, 2002), y muchas otras más donde los beneficios económicos que se generan de la actividad forestal se asumen como algo muy importante.

La apropiación no es un proceso estático ni acabado. Las experiencias previas que han superado colectivamente no sólo descubren entre sus miembros la capacidad de gestión como grupo, sino que conforman la base para consolidar una apropiación del territorio y de los recursos forestales, para propiciar el desarrollo de instituciones y diseñar formas de organización más efectivas para su aprovechamiento.

$\mathrm{H}$ asta ahora se descubre entonces que el análisis de apropiación del territorio es relevante en este tipo de estudios como complemento al análisis de los principios de diseño, porque permite mostrar las causas que sostienen el comportamiento de cooperación o no comunitaria en el desarrollo de instituciones en torno al recurso de uso común. 


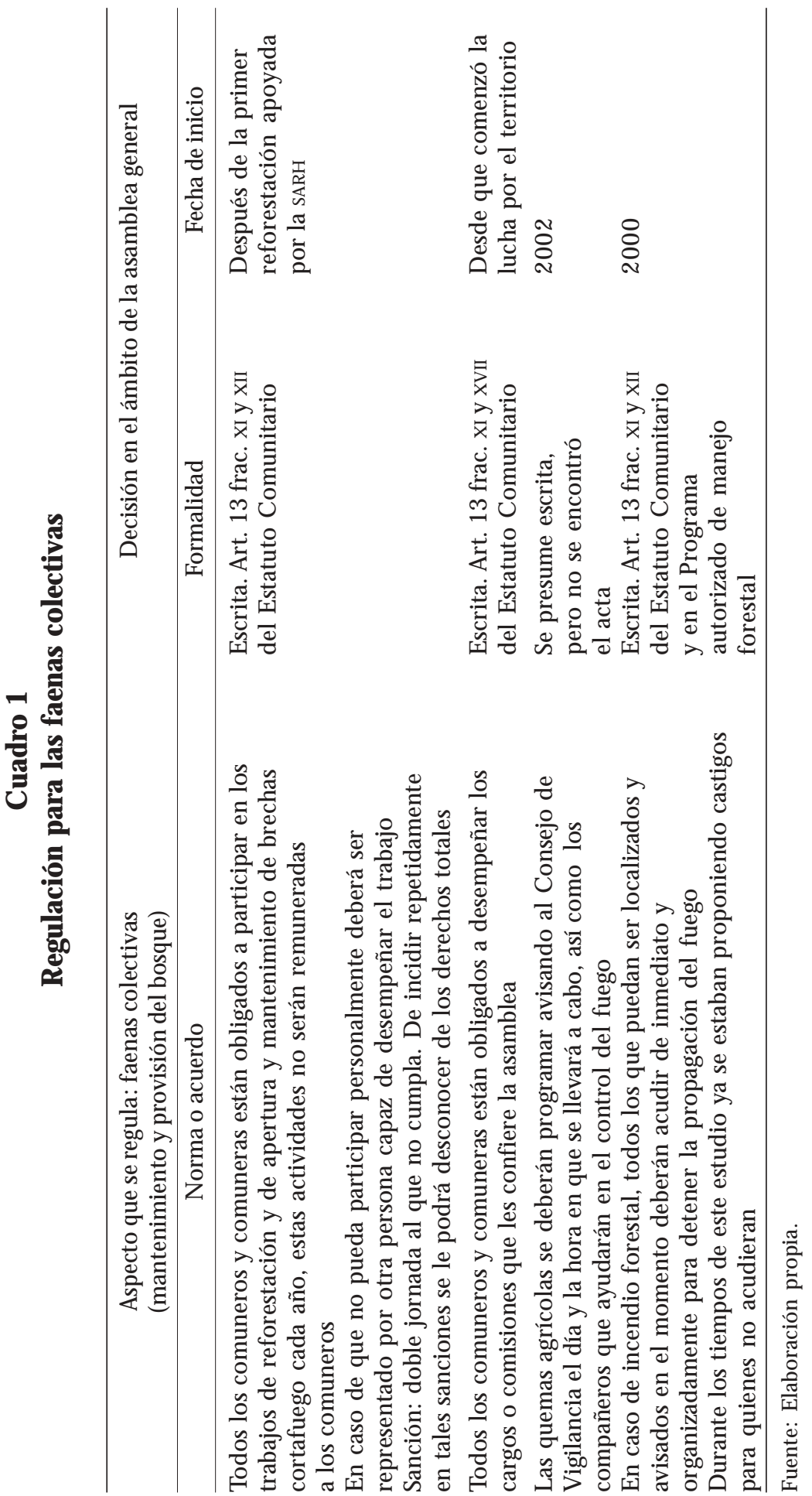




\subsection{Los prinaipios de diseño en el marco del enfoque institucional}

4.2.1. Límites claramente definidos y sistema de reglas colectivas para tiempo, lugar, forma y cantidades del recurso

De acuerdo con O strom (1990), en las instituciones locales sólidas los dueños del recurso mantienen límites claramente definidos. En este estudio consideramos el límite de usuarios con derechos, los límites del recurso forestal y los límites de su propiedad. En cuanto al límite de usuarios encontramos que está bien definido. En la comunidad se reconoce a 178 comuneros con voz y voto para decidir sobre el territorio y el aprovechamiento de sus recursos naturales. Además internamente se sabe quién es comunero y quién no; en M éxico la SRA (gobierno federal) reconoce oficialmente al comunero o ejidatario al expedir actas de reconocimiento y titulación de bienes comunales o ejidales, por tanto, es comunero quien posee título de derechos comunales.

Se encontró que $80 \%$ de los comuneros entrevistados identifica claramente las distintas áreas forestales y los límites de la comunidad. Q uienes han ocupado cargos de vigilancia conocen mejor las áreas de bosque y sus linderos. A demás, las faenas colectivas - como construir brechas cortafuego, chapeo y reforestación- han permitido distinguir mejor los límites de su territorio.

El $70 \%$ de los comuneros conoce las áreas forestales donde cada año se aprovecha madera en rollo para comercializar. Desde el 2000 el programa de manejo contempla 542 ha de bosque de pino y de pino-encino en las que se definieron áreas de corta anual, cuya ubicación la mayoría de los comuneros distingue fácilmente, al igual que las establecidas para conservación y restauración. En estas últimas no se extrae leña para no perturbarlas, mucho menos se usan para cultivo. Para extraer leña, la comunidad acude a sus bosques de encino, los cuales considera abundantes y se ubican en zonas de menor altitud. Para fines agrícolas, se tienen 541 ha de áreas comunales, que aunque estén parceladas y durante años se han usado individualmente, la asamblea tiene autoridad para decidir sobre las mismas.

Si no se tienen claros los límites de propiedad, se corre el riesgo de que otros cosechen los beneficios que con tanto esfuerzo sus dueños han producido. O tro riesgo es el de no delimitar el número de usuarios, pues si a todos se les permite el acceso, y la demanda de unidades del recurso se eleva, "el potencial destruc- 
tivo podrá hacer que la tasa de descuento ${ }^{17}$ usada por los dueños se eleve a un 100\%" (0 strom, 1990; 149). En esta comunidad se han establecido estos tipos de límites y la mayoría de los comuneros los identifica claramente.

Para citar un ejemplo, el ejido Cerro Prieto, en M ichoacán, conoce muy bien los linderos de su propiedad, de sus bosques y hasta dónde abarca la Reserva de la Biosfera de la $M$ ariposa M onarca. Contrariamente, en el ejido Cafetal ubicado al sur de Quintana Roo, se presenta una pobre delimitación de sus áreas de bosque, lo que ha generado conflictos en los derechos del grupo hacia sus recursos comunes, y aún peor, presentan una débil regulación local, lo que ha ocasionado amplios desmontes de sus bosques (M erino, 2004).

También se encontró que existen acuerdos sobre cantidades fijas para extraer leña o madera para sus viviendas, es decir, se tienen límites definidos de a cuánto recurso puede acceder cada uno y además se han establecido las veces que cada comunero tiene derecho a solicitarlo en el año (cuadro 2).

\subsubsection{El surgimiento de conflictos y los mecanismos comunita- rios de solución}

Según condiciones establecidas por el Fondo Nacional de Fomento Ejidal (Fonafe), ${ }^{18}$ los primeros ingresos de la venta de madera deben reinvertirse en obras de beneficio económico 0 social comunitario. Fue así que la comunidad reinvertía en obras que generaran más beneficios económicos, como la renta de un molino de granos y proyectos de elaboración de tejas y ladrillos. Desde el principio, la rendición de cuentas de los ingresos obte-

\footnotetext{
${ }^{17}$ Tasa de descuento es el grado en que se deprecia un bien en el futuro. Un bosque puede tener alta tasa de descuento para sus dueños cuando ellos valoran sus productos en el corto plazo o de inmediato. Cuando los dueños invierten actividades en sus bosques que sólo generarán sus frutos a largo plazo, se dice que el bosque mantiene una baja tasa de descuento.

18 "El Fonafe era un fondo gubernamental que contaba con operadores de campo, y que se había integrado con los derechos de monte entregados durante décadas como pago por las extracciones en los bosques comunales. Por ley, $70 \%$ de estos fondos se depositaban en cuentas bancarias que el Fonafe mantenía a nombre de las comunidades, y el $30 \%$ adicional se pagaba directamente a las comunidades. Este fondo se convirtió en parte de un amplio espectro de iniciativas de promoción del desarrollo rural durante la administración del presidente Luis Echeverría (1970-1976). Fue en este periodo cuando se organizaron las primeras asociaciones o uniones de ejidos. La reforma al Artículo 146 de la Ley Federal Agraria en ese tiempo abrió espacios para las asociaciones económicas entre ejidos" (M oguel y López Sierra, 1990, en Bray y M erino, 2004: 57).
} 


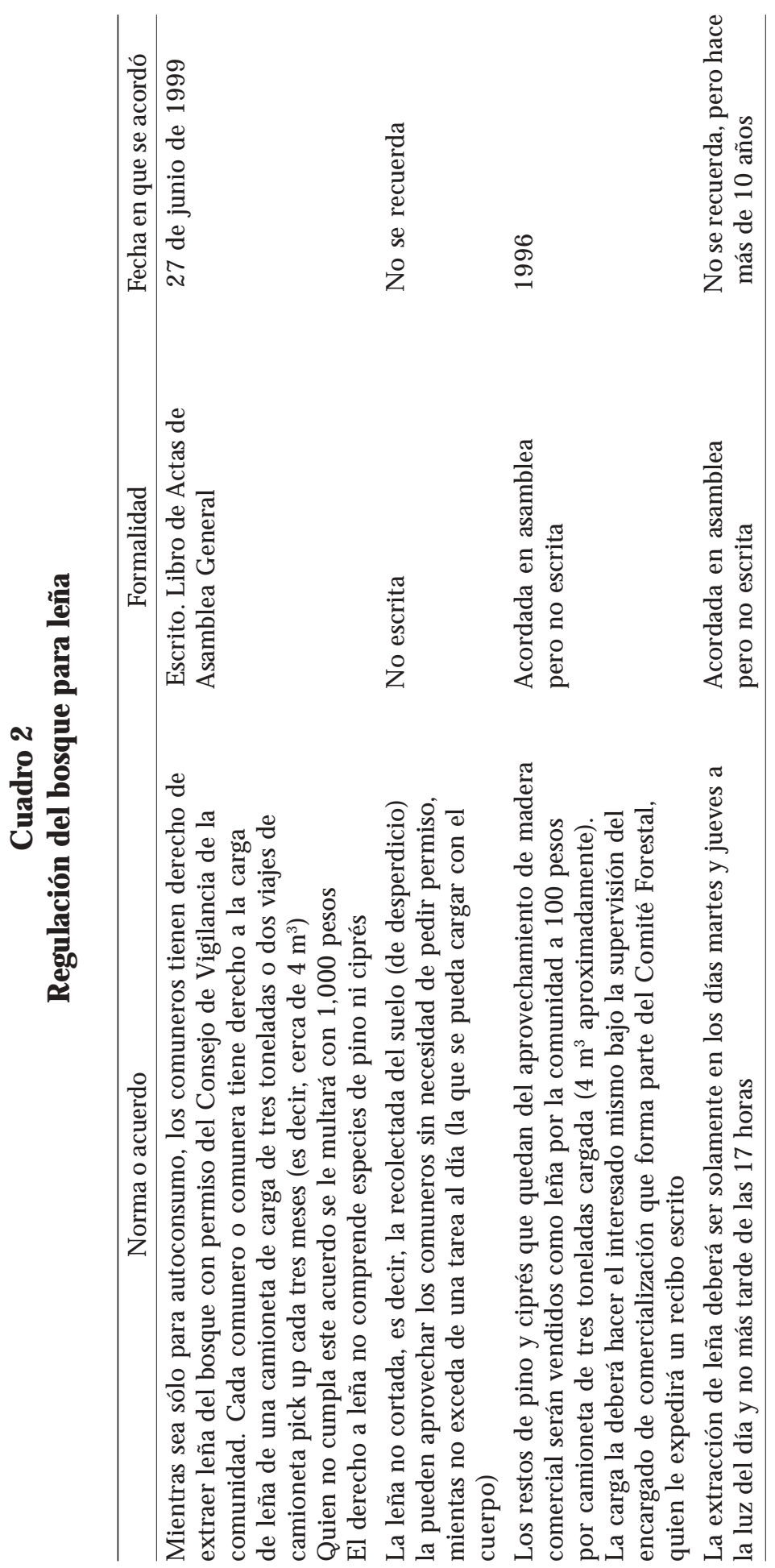




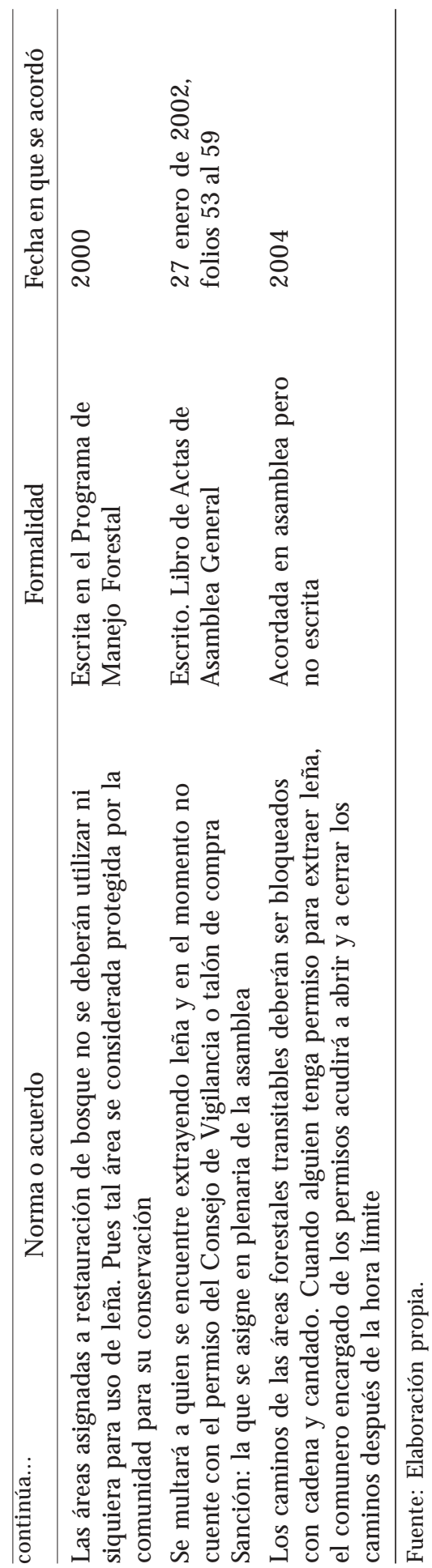


nidos por estos proyectos fue muy imprecisa. La falta de mecanismos de control colectivo en cuanto a los beneficios obtenidos, ya sea por actos de corrupción, por descuidos o por falta de capacidades en el control de las cuentas, generó un ambiente de desconfianza entre los comuneros. Al hablar de propuestas para otros proyectos colectivos, los comuneros manifiestan apatía en aprobarlos, pues aún no cuentan con mecanismos de rendición de cuentas satisfactorios. A partir de la inconformidad en el manejo de los ingresos, las reglas que entonces se tenían fueron aumentando y haciéndose más rígidas. La vigilancia se hizo más fuerte en los trabajos de monte, pero en cuanto al manejo de cuentas, se evitó que el dinero quede mucho tiempo guardado y se asigna a alguien que vigile al responsable.

Para evitar tentaciones de robo y estar más seguros del igual reparto financiero, la comunidad ha decidido no reinvertir sus ingresos en otros proyectos. Se tiene el acuerdo de que el dinero se saca del banco y se reparte justo después de concluir la venta total anual de madera. Así se distingue un principio comunitario muy importante: repartir por igual los beneficios de la madera vendida para evitar tentaciones de quien lo administra. El mismo principio de igualdad se distingue también en la distribución de los costos de cooperación económica y de las faenas colectivas que todos por parejo deben ejercer.

La estructura de cómo se representan las autoridades de los ejidos y comunidades en M éxico es muy similar (Bray et al., 2006). Expresar el problema ante los demás, en las reuniones de comités o de la asamblea es el principal mecanismo para resolver los conflictos y confusiones en la información compartida. Es en este mismo espacio donde los integrantes de Comunidad Teopisca discuten todos sus asuntos, donde se tratan los problemas, se toman decisiones, y al gunas veces quedan asuntos pendientes cuando no se cuenta con información suficiente para decidir. Durante la investigación de campo se presenciaron diversos conflictos, gran parte de ellos a causa de una comunicación deficiente entre los comuneros. Los conflictos que surgen sobre la rendición de cuentas provocan que se redefinan tanto las reglas ya establecidas como una mejor vigilancia en el manejo de los ingresos, así como sanciones más eficaces que garanticen el principio que rige primero la toma de decisiones: el de igualdad tanto en los costos como en el reparto de los beneficios colectivos. Las dudas o la falta de información, sea oficial o técnica para tomar decisiones, se consultan con el prestador de servicios profesionales, y cuando corresponde 
a asuntos de apoyos o restricciones gubernamentales, directamente se pide asesoría a los funcionarios.

Elinor Ostrom (1990) sostiene que si los individuos que cometen faltas o presentan problemas personales que les impida seguir una regla o acuerdo y no disponen de mecanismos que les permita discutir y resolver las causas del problema y justificar su falta de desempeño, entonces las sanciones podrían llegar a verse como injustas y los niveles de cumplimiento disminuirían.

En este caso, la Comunidad de Teopisca privilegia la comunicación en la asamblea general y las reuniones de los diferentes comités para el intercambio de ideas y para aclarar los conflictos, con la finalidad de solucionar los problemas que afecten en lo colectivo.

\subsubsection{Diseño de reglas y organización en múltiples niveles anidados}

Como último principio, la apropiación, el aprovisionamiento, el seguimiento, el cumplimiento, la resolución de conflictos, así como establecer reglas y tomar decisiones se organizan en varios niveles de organismos anidados. De acuerdo con Elinor O strom (1995), resulta más complicado diseñar reglas sobre provisión y aprovechamiento del recurso común en un solo nivel de organización. Ante esto, se encontró que desde el principio, la comunidad decidió organizarse en las estructuras de autoridad y responsabilidad típicas de los ejidos, establecidas en la Ley Agraria (ley federal). La asamblea, junto con todos los comuneros, representa la autoridad principal en la comunidad y se reúne al menos una vez al mes, pero se tienen otros niveles anidados de organización. El órgano que representa a la asamblea general es el comisariado, compuesto por presidente, secretario, tesorero y sus respectivos suplentes. O tro es el Consejo de Vigilancia, que se compone de los mismos cargos que el comisariado y se encarga de supervisar la transparencia en los procesos de gestión, concede permisos para recolección de leña o para faltar a las reuniones. También se encarga de programar las quemas agrícolas ${ }^{19}$ y de vigilar las áreas de bosque. En menores niveles, pero de mucha importancia, se estructuran otros órganos anidados en la asamblea que tratan asuntos más operativos respecto de algún

\footnotetext{
${ }^{19}$ En el Consejo de Vigilancia se acuerdan aspectos como qué día se ejercerán las rondas por el bosque; cuándo y a qué hora sólo se permite extraer leña, de qué lugar se puede extraer leña; qué día y entre qué horas se hacen las quemas agrícolas con la intención de evitar propagación de fuego que provoque incendio forestal, entre otras.
} 
proyecto o responsabilidades que se deben organizar. Entre estos órganos se encuentran el Comité Forestal de Aprovechamiento ${ }^{20}$ y el Comité del Vivero, que son los órganos encargados de los asuntos forestales de la comunidad, pero que dependen de las decisiones generales de la asamblea.

Desde el año 2000 la comunidad mantiene un vivero para reproducir plántulas de coníferas para la reforestación anual. Con el objetivo de garantizar el funcionamiento del vivero se cuenta con un comité compuesto por cuatro personas. Las funciones de este comité comprenden manejar los fondos de cooperación; ${ }^{21}$ cubrir los gastos ya sea de los insumos necesarios para los trabajos de monte, o de los pagos de jornales; y finalmente, se encarga de organizar las actividades de reforestación y la comercialización de plántulas remanentes del vivero. El proyecto del vivero recibe asesoría continua de forma gratuita del personal de la Semarnat y la Conafor regionales. Cada año, el Comité del Vivero, como todos los órganos en que se organiza la comunidad, debe rendir cuentas a la asamblea de los ingresos que generó.

El Comité Forestal de aprovechamiento es más complejo. Se conforma por 12 comuneros encargados específicamente de las actividades de aprovechamiento forestal maderable. Sus integrantes, al igual que los del Comité de Vivero, cambian cada año por tres razones: 1) con el fin de que todos lleguen a ocupar los distintos cargos y tengan la oportunidad de aprender sobre manejo forestal; 2) porque en casos de corrupción, malos manejos en los ingresos o desorganización, los problemas no durarán más de un año; y 3) porque tener un cargo, cualquiera que sea, se considera una gran responsabilidad que la mayoría prefiere no tomar. El deber en la comunidad es aceptar el cargo que se le asigne, así, para ellos es bueno que la carga del puesto no dure más de un año. En caso de que se desee volver a ocupar los cargos de cualquier comité, el interesado debe proponerlo en los momentos de la asignación. En la comunidad los cargos de la mesa directiva, como el comisariado y el Consejo de Vigilancia son los únicos órganos de autoridad que duran tres años, como lo indica la Ley Agraria en su artículo 39.

${ }^{20}$ En el Comité Forestal se celebran reuniones cada sábado en las temporadas de extracción de madera comercial y secundaria. Ahí se discuten los asuntos de depósitos bancarios y los problemas de los trabajos de monte.

${ }^{21}$ Para solventar los gastos del vivero, desde el año 2000 se obtiene un fondo mediante la cooperación de 10 pesos (poco menos de un dólar estadounidense) de cada comunero y se apoya con la comercialización de plántulas. 
A lo largo del tiempo la comunidad ha logrado diseñar colectivamente un amplio sistema de reglas, tanto en la asamblea como en los comités. ${ }^{22}$ Algunas reglas se diseñaron bajo la influencia del gobierno en el sector forestal regional para hacer cumplir las leyes forestales estatales y federales, pero hasta el momento el complejo normativo lo entiende la mayoría de la comunidad. Una serie de reglas dictan los trabajos de monte (cuadro 3), Ias faenas colectivas $^{23}$ (cuadro 1), así como la cantidad, tipo de árboles, horarios, áreas restringidas y demás condiciones para el acceso a leña (cuadro 2). Algunas reglas se acuerdan explícitamente y se formalizan en actas, mientras que otras son más bien acuerdos que se asumen de manera implícita, se entienden y se espera su cumplimiento por las costumbres locales.

El reparto de los beneficios y los costos derivados de los recursos forestales se basa en el principio de igualdad. Con base en este sistema de reglas, la comunidad ha podido afrontar los casos de quienes intentan beneficiarse más de lo que les corresponde, evitar la desigual cooperación de los comuneros y así prolongar la disponibilidad del recurso a través del tiempo.

En este estudio no se intenta asumir que el sistema de instituciones de gestión de esta comunidad constituye el modelo ideal, sino que cada grupo o comunidad desarrollará sus instituciones de acuerdo con su propio proceso de gestión local, que corresponde a problemas tal vez parecidos pero que se presentan en tiempo y forma distinta. Además, es importante reconocer que el desarrollo de tales instituciones es resultado de un arduo trabajo colectivo durante más de 30 años, un tiempo relativamente corto en comparación con tantos otros sistemas de recursos administrados por comunidades que llevan cien o cientos de años, algunos hasta miles de años de haberse desarrollado (O strom, 1990). Estas reglas comunitarias, a su vez, han hecho frente a diversas amenazas constantes que pueden atentar contra la estabilidad del sistema de recursos forestales, como las presiones de mercado, las políticas de fomento agrícola, el crecimiento poblacional, entre otras (como las que señalan Angelsen y Kaimowitz, 1999).

Se han documentado casos similares en diversos lugares de M éxico (Bray et al., 2006), pero también en países como la In-

${ }^{22}$ Reglas de elección colectiva y operativas que O strom (1990) identifica que se diseñan en diferentes niveles anidados.

${ }^{23}$ Como las actividades colectivas de prevención y tratamientos sanitarios de los árboles, reforestación, podas, prevención de incendios, aclareos y otras de fomento y cuidado al bosque. Estas acciones aseguran el sostenimiento a largo plazo del sistema de recursos (O strom, 1990). 


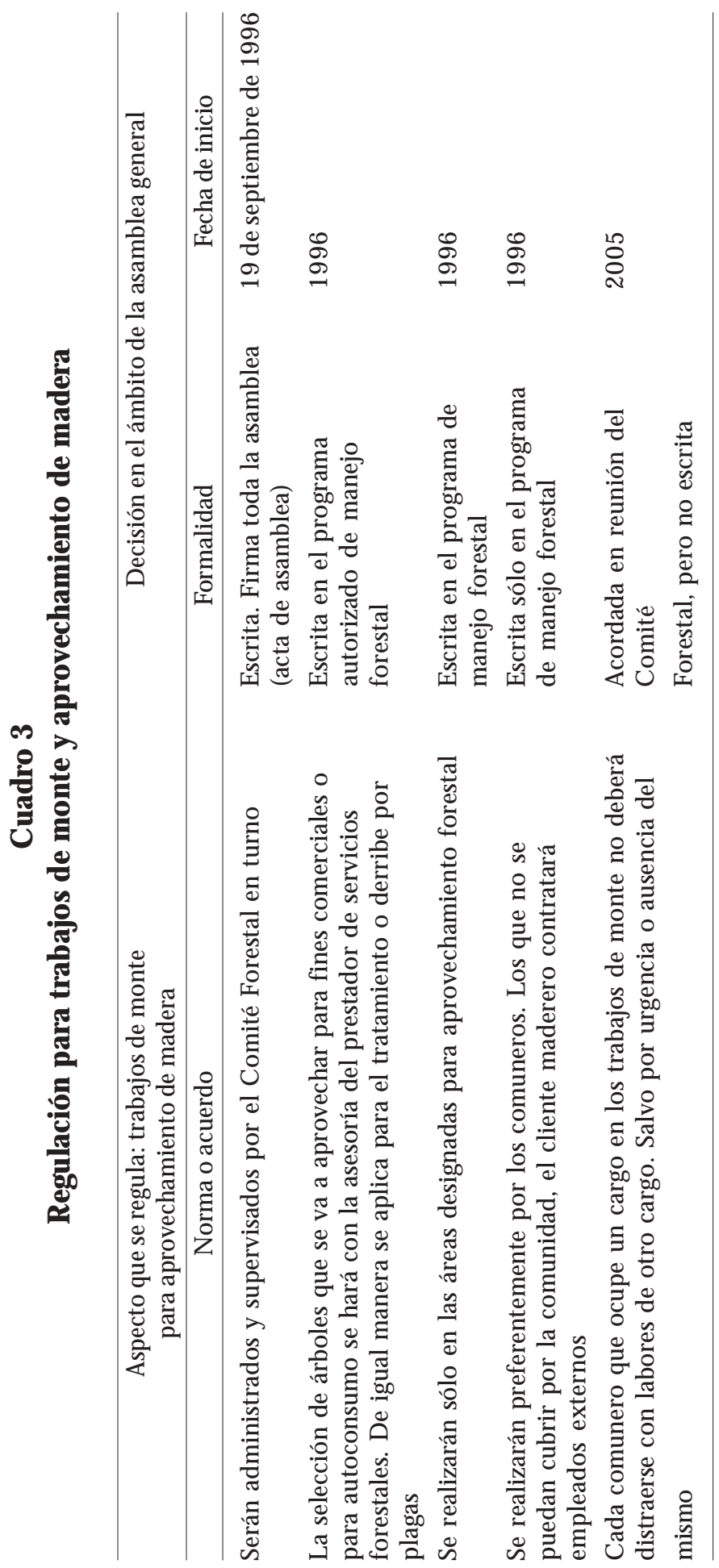




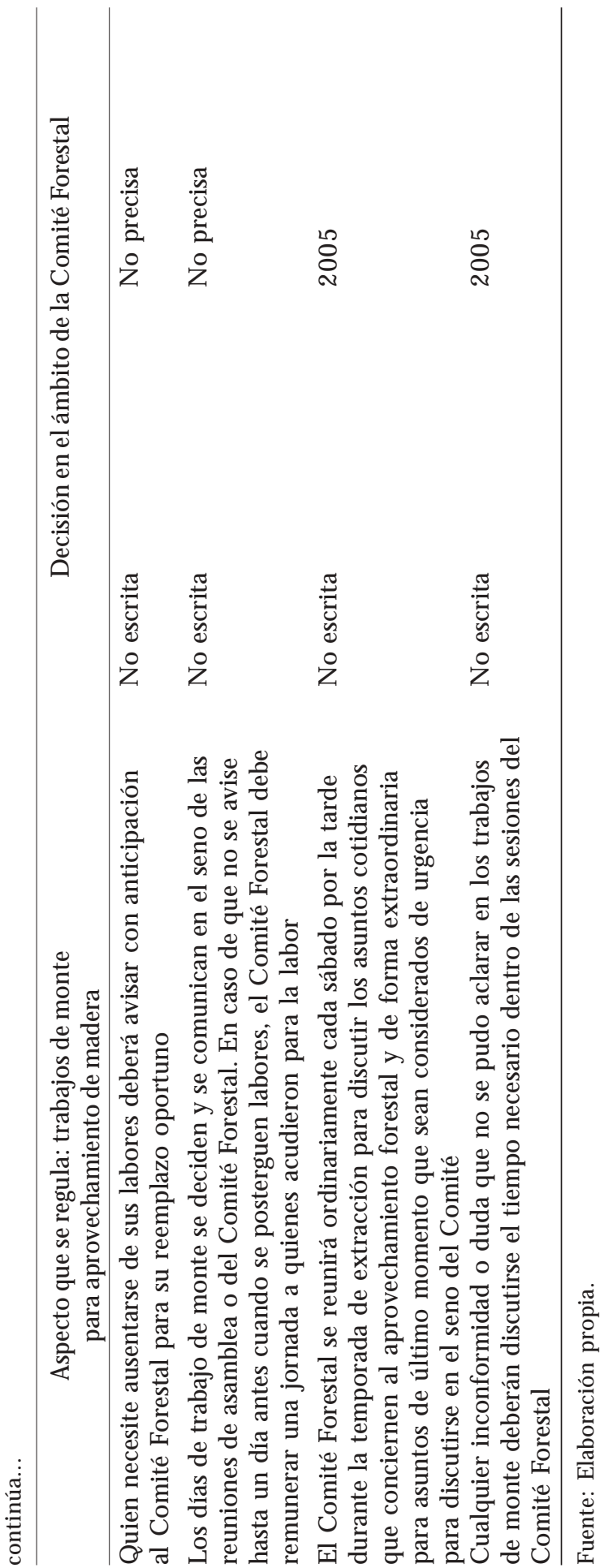


dia, Agrawal (2005) encontró que en los consejos locales de Kumaon, las comunidades deciden quiénes pueden utilizar los bosques, cuánto es posible cosechar, cuánto deben pagar y cómo proceder si no cumplen las normas. Aquí, el autor señala que las comunidades cuidan mejor sus bosques ahora porque el gobierno les respeta sus derechos; también porque se dan cuenta que ciertos productos forestales son cada vez más escasos. Pero más importante todavía es la mayor participación de sus integrantes en las actividades forestales.

\subsubsection{Vigilancia y sanciones}

En este trabajo se identificaron procedimientos comunitarios para vigilar el bosque y el manejo de los ingresos económicos y cooperaciones hechas por los comuneros. En la asamblea general se aplican diferentes sanciones por las faltas cometidas, para quienes reinciden la sanción es claramente conocida, hay multas hasta por 1,000 pesos para quien no pida permiso para extraer leña y hasta 2,500 para quien corte un árbol maderable sin permiso, aunque esta última falta sólo se ha cometido una sola vez, lo que ofendió a la mayoría de los comuneros y fue motivo para establecer esta multa. Por otro lado, no se tiene establecida la sanción para las faltas más leves y menos comunes. Cuando estas ocurren, se define públicamente la sanción en las reuniones de asamblea. En este caso, quien cometa la falta se encuentra bajo la incertidumbre del grado de sanción que se le dictará. La sanción más severa es la exclusión de los derechos de comunero. En menos de cinco años se ha destituido a dos comuneros por faltar en repetidas ocasiones a las faenas colectivas.

Casi siempre los madereros actúan buscando ventajas de la comunidad, como tratar de sobornar a los comuneros que cubren estos cargos para que cuenten a su favor la madera cargada. Un par de ocasiones lo han logrado cuando la comunidad no asignaba puestos de vigilancia, entonces se sancionó fuertemente estas acciones y mejoró la supervisión. La sanción más aplicada es la social, la que atenta contra el prestigio, es decir, el ser descubierto, juzgado y criticado ante todos y verse en la necesidad de pedir disculpas frente a la asamblea general. Los comuneros consideran que las sanciones son necesarias para hacer cumplir los acuerdos tomados.

En cuanto a las sanciones, estudios experimentales de G ürerk et al. (2006) demuestran que el hacer uso de ellas es un factor 
determinante para motivar acciones de cooperación y orden social en los grupos humanos. Para este caso, ocasionalmente los comuneros han elevado el grado de sanción para las faltas más cometidas. Casi para concluir este estudio, los comuneros hablaban de establecer multas a quienes no acudan al Ilamado urgente de control de incendios, pues algunos se hacen de la vista gorda para no acudir.

Sobre la vigilancia y la supervisión, antes se mencionó que el manejo de las cuentas no ha sido del todo satisfactorio para la comunidad, pues muchos comuneros tendrían que confiar en la palabra porque no saben leer ni escribir y quienes saben llevar bien las cuentas no las presentan lo suficientemente transparentes. Aunque los comuneros mayores manifiestan desinterés por aprender a leer y escribir, los jóvenes que van ingresando porque heredaron los derechos de comunero, tienen mejores capacidades para el manejo de cuentas, y es a ellos a quienes actualmente se está asignando esta responsabilidad. Cabe aclarar que el que sean alfabetizados tampoco garantiza que se eviten actos de corrupción, pero sí contribuye a fortalecer los mecanismos de vigilancia y la transparencia en el manejo de los ingresos. Las mayores capacidades de los comuneros se traducen en mejorar el capital humano; y un mejor capital humano fortalece la confianza y el desempeño del capital social de la comunidad.

En cuanto al monitoreo relacionado con los recursos forestales, el consejo de vigilancia realiza rondas sin previo aviso en diversos sitios para evitar el saqueo de intrusos y evitar daños por incendios provocados por vecinos. Los comuneros expresan que en la parte de bosque colindante con la comunidad Amatenango se presentan este tipo de problemas. En las fechas de mayor incidencia, la comunidad asigna anualmente tres grupos de 20 personas que se turnan la vigilancia dentro del bosque haciendo recorridos hasta sus linderos.

Q uienes supervisan las condiciones del recurso pueden ser 0 no los propios dueños. M ientras que muchos bosques los protege el gobierno con guardias forestales contratados (por ejemplo, las áreas naturales protegidas, AN P), en esta comunidad la supervisión (vigilancia) la hacen los comuneros mismos. En los bosques de uso común, como es este caso, la vigilancia es un cargo obligatorio. M ás bien, son actividades vistas como un servicio comunitario con el interés de sus poseedores en garantizar que las reglas se cumplan. 
4.2.5. Reconocimiento e influencia de los asesores externos, la política forestal y sus proyectos impulsados

No todo se ha dado por iniciativa única de los comuneros, en los apartados anteriores se describieron los momentos de participación del gobierno, como la lucha por la tierra, las reforestaciones que promovió la SARH y las recomendaciones fitosanitarias de los pinares, así como la capacitación en los trabajos de monte y faenas colectivas que hoy sabe desempeñar la comunidad.

\subsubsection{Las políticas forestales}

Las políticas ambientales y de desarrollo han tenido una marcada influencia, pues cuentan con la facultad oficial de prohibir 0 permitir el aprovechamiento forestal dependiendo de la calidad del bosque y la planeación del manejo que se le dará. D esde principios del siglo $x x$ las leyes y políticas forestales mexicanas han influido en la gestión local de los recursos forestales, como vedas y concesiones de extracción forestal, las cuales no consideraban los privilegios de los campesinos. Desde los años setenta las políticas forestales ya se abrían a la participación campesina y en ciertos estados se impulsaron empresas forestales comunitarias bajo el Fonafe, ${ }^{24}$ mientras que en Chiapas el apoyo fue casi nulo y muchas veces demorado. Es precisamente a comienzos de esta misma década que, después de una intensa gestión de lucha por la tierra, la Comunidad Teopisca apenas adquiere reconocimiento oficial como comunidad.

En los años ochenta se intensifican en todo el país las brigadas de reforestación y con la ley forestal de 1986 se contribuye al desarrollo forestal comunitario. Fue al siguiente año que la Comunidad Teopisca comercializó su primera extracción de madera que presentaba problemas fitosanitarios, y que luego invirtió sus ingresos en tierras agrícolas más productivas. Justo después, al finalizar los años ochenta, se presenta en Chiapas una veda forestal que limita las extracciones comerciales.

Chiapas, desfasada en el ejercicio de las políticas federales, establece mediante el gobierno estatal esta veda mucho después de que en el resto del país ya se consideraba una política obsoleta. Después, en 1992, una vez modificado el Artículo 27 de la

${ }^{24}$ Cincuenta y dos empresas comunitarias en Durango, 42 en Chihuahua, 11 en Quintana Roo, nueve en Campeche, ocho en M ichoacán y tres en Oaxaca (Bray y Merino, 2004). 
Constitución (que ahora permite disolver la propiedad común), 25 se aprobó una nueva ley forestal federal orientada por el modelo neoliberal. Esta nueva ley promovió sobre todo las plantaciones forestales para fines de mercado (Téllez, 1994, citado por Bray et al., 2006). Además instituyó el Consejo $\mathrm{N}$ acional Forestal T écnico Consultivo, representado por instancias gubernamentales, académicos, industrias, oNG y organizaciones campesinas relevantes. A su vez, estableció la creación de consejos regionales o estatales donde debían estar presentes los gobiernos municipales (Bray y M erino, 2004).

En 1997, un año antes de que a la comunidad le suspendieran oficialmente la autorización para ejercer el primer programa de manejo forestal, ya se había modificado una vez más la ley forestal con la promoción de tres aspectos principales: regular el manejo de los bosques naturales, incrementar las vías para el soporte de la forestería comunitaria, así como regular y apoyar el establecimiento de plantaciones forestales ${ }^{26}$ (Bray et al., 2006; Bray y M erino, 2004). En el año 2000, a partir del Programa para el Desarrollo Forestal (Prodefor) que promovió esta ley, se apoyó a la comunidad con financiamiento $(28,600$ pesos, equivalentes a cerca de 2,600 dólares) que cubrió en parte los costos de una nueva planeación de manejo, como mencionamos antes, dirigido por un nuevo PSF.

La última modificación a la política forestal se hizo en 2003, con la que se creó la Comisión N acional Forestal (Conafor) como un alto órgano operativo dependiente de la Secretaría de M edio Ambiente y Recursos $\mathrm{N}$ aturales (Semarnat), la cual se hace responsable de promover y preservar los bosques mexicanos. En esta ley se hace prioritario incrementar el presupuesto de los programas de desarrollo forestal impulsados desde la política anterior y que estos programas orienten el desarrollo forestal

${ }^{25}$ Durante décadas, el Artículo 27 respaldaba la inalienabilidad, imprescriptibilidad e inembargabilidad de la tierra bajo propiedad común, pero fue en este año cuando, a raíz del modelo globalizado, el artículo 27 da un giro permitiendo que los ejidos y comunidades se privaticen, vendan o embarguen. Para muchos, se pierde la importancia cultural que une a los pueblos con la tierra comunal por el hecho de que sea posible privatizarla. La modificación al Artículo 27 ha sido fuertemente cuestionada, pues la propiedad común de las tierras en M éxico ha sido base esencial de la cultura y vida de los pueblos rurales.

${ }^{26}$ Estas posiciones originaron apoyos gubernamentales como el Programa para el Desarrollo Forestal (Prodefor), el Proyecto de Conservación y M anejo Sustentable de Recursos Forestales en M éxico (Procymaf), el Programa de Apoyos para el Desarrollo de Plantaciones Forestales Comerciales (Prodeplan), y el Programa N acional de Reforestación (Pronare). 
comunitario en cadena productiva. ${ }^{27} \mathrm{M}$ ientras tanto, en Chiapas, a partir de la constante tala ilegal de bosques y selvas, durante 2001-2006 se implementó una estrategia punitiva para quien comercialice madera sin permiso oficial, pero que ha dejado de lado establecer alternativas integrales en torno al problema de la excesiva tala clandestina en las comunidades y ejidos. Por su parte, el gobierno estatal organizó comités regionales de inspección y vigilancia operativos que se encargan de vigilar los actos ilícitos de tráfico de madera. A pesar de esto, en Los Altos de Chiapas los delitos forestales tienen una alta incidencia, como sucede en el ámbito estatal. ${ }^{28}$ De manera simultánea, el gobierno estatal ha financiado el establecimiento de viveros altamente tecnificados en distintos ayuntamientos que, al menos hasta 2005, en la región de Los Altos han resultado en inversiones tipo el efantes blancos que han sido abandonadas porque son decisiones tomadas desde altas escalas, sin considerar del todo las necesidades locales. Lejos de solucionar los problemas, sólo han mermado la disponibilidad de las comunidades y ejidos en las iniciativas que pudieran ofrecer mejoras a largo plazo en los bosques. Para entonces, la Comunidad Teopisca ya no necesitaba de estos viveros de alta tecnología, pues ya contaban con uno propio y lo impulsaron más usando tecnología tradicional.

\subsubsection{Los asesores y actores externos}

$M$ ientras numerosos ejidos y comunidades no cuentan con una mejor alternativa que la tala forestal ilegal, otros como la Comunidad de Teopisca se han relacionado muy de cerca con los asesores externos, como en su tiempo la SARH, que los asesoraron desde el principio en su gestión por la tierra, y ahora también con Conafor, Semarnat y el PSF. Los comuneros consideran que la asesoría les permitió mejorar el aprovechamiento forestal. Las recomendaciones técnicas, como la venta de madera de árboles plagados, las reforestaciones, los planes de manejo y las capacitaciones para emplearse en los trabajos de monte, son experiencias que hoy ex-

${ }^{27}$ Ver http://www.conafor.gob.mx/programas_nacionales_forestales. Este sitio Web se consultó el 2 de agosto de 2005.

${ }^{28}$ Estos testimonios son parte de los problemas críticos presentados por funcionarios del sector forestal, actores municipales y procuradores de la Profepa y la PGR regionales que integraban el Grupo de Gestión Regional de la Comisión de Inspección y Vigilancia Forestal de la Zona Altos de Chiapas, en el taller de planeación elaborado en plenarias los días 16 y 18 de febrero de 2005 en San Cristóbal de Las Casas, Chiapas (datos fundamentados en minuta y en grabación de audio). 
plican por qué la comunidad se mantiene cerca de estos actores para consultar asuntos sobre técnicas de manejo, tramitación de apoyos gubernamentales o cuestiones legales de aprovechamiento. Pero aun así, los comuneros sienten que ellos por sí solos no pueden hacer un buen manejo forestal, y que el servicio de los profesionales es indispensable. El $97 \%$ de los comuneros respondió que les gustaría recibir capacitación y no depender tanto del PSF para dominar las técnicas de manejo del bosque.

Aun con lo anterior, no todo lo que los actores externos proponen lo acepta fácilmente la comunidad. Los comuneros no dejan de lado evaluar el riesgo de seguir al gunas recomendaciones, siempre analizarán los costos y la incertidumbre que está en juego de acuerdo con los beneficios que presume determinada propuesta. En especial nos referimos a los proyectos de ecoturismo o de aserrío propuestos por los funcionarios y que han sido rechazados por la comunidad. El $42 \%$ de los comuneros no acepta estos proyectos porque no todos se beneficiarían igualitariamente, pues sostienen que dejarían de distribuirse entre to dos los costos y los beneficios de actividades colectivas, mientras que $40 \%$ opina que estos proyectos son necesarios para avanzar en la empresa forestal y darle valor agregado a la producción actual. El resto dice no entender bien los proyectos en sí.

En este sentido, se observa una división de intereses que dificulta la gestión local para lograr nuevos pasos en el desarrollo forestal de la comunidad como antes se ejercía. El principio de igualdad en los costos y beneficios colectivos ha funcionado para otras acciones emprendidas, como el que todos reforesten, poden o se turnen anualmente los cargos de, por ejemplo, el Comité Forestal o el del Vivero, pero no se adapta a los proyectos de ecoturismo y aserradero porque han sido propuestos bajo un modelo más gerencial, además porque no aseguran la igualdad de condiciones para todos. No se puede estar reeligiendo anualmente a quien corta la madera en un aserradero, o a los guías de turistas o al administrador en el caso de un proyecto ecoturístico, además para ciertas actividades será necesario saber leer y escribir, lo que excluiría a muchos, etc. En este sentido, la comunidad se encuentra en un proceso de confiar en las nuevas generaciones para estar preparados en proyectos futuros como el aserrío o el ecoturismo.

Además, estos proyectos no son muy atractivos para la comunidad porque llegan como una propuesta externa y sin la planeación participativa de los comuneros. El posible éxito en el ase- 
rrío para la mayoría de ellos es un proyecto de incertidumbre. A la fecha, la comunidad no ha trabajado antes un aserradero, por lo que carecen de la experiencia previa que podría contribuir a su aceptación y que a largo plazo ejerza una apropiación de la comunidad ante el proyecto. La incertidumbre ante estas iniciativas es tal que representa un alto riesgo al momento de decidir aceptarlos o no, un riesgo tanto individual como colectivo.

A pesar de ello, se identificó una clara disponibilidad de los comuneros para evaluar las recomendaciones de los funcionarios y asesores, como el PSF. Estos actores externos, a su vez, se encuentran en un proceso de conocer e integrar sus propuestas a la dinámica local. Cabe aclarar que al mismo tiempo estos asesores tropiezan ante las exigencias oficiales de hacer cumplir las políticas y normas en tiempo y forma mediante complicados trámites para el apoyo a los usuarios. En este sentido, el sistema oficial del sector no siempre facilita lograr un manejo que combine la participación y los conocimientos de los comuneros con los conocimientos profesionales de manejo (Klooster, 2002), y a su vez, cumplir con los requerimientos de protección ambiental de la política forestal, es decir, lograr algo que podemos llamar un manejo forestal coordinado. Al momento, la política forestal no permite la apropiación total de los manejos forestales comunitarios, pues establece la dependencia permanente de un asesor externo que planea y dirige los aprovechamientos forestales, es el caso del PSF.

\subsection{El estado del reaurso forestal}

Para hablar del análisis del recurso forestal, cabe mencionar que su estado está determinado por causas multifactoriales que actúan desde distintos niveles, tanto directa como indirectamente, por mencionar algunas: el crecimiento poblacional y la densidad de población, el acceso al recurso forestal, la pobreza y la tecnología; así como la deuda nacional, la política gubernamental o la estabilidad política, entre otras (Gibson et al., 2000; Angelsen y Kaimowitz, 1999).

Pero precisamente, como se mencionó al principio, muchos casos estudiados han encontrado una relación estrecha entre la acción colectiva organizada por un recurso forestal de propiedad común y el estado del recurso mismo (Gibson et al., 2000; O strom, 1990; M erino, 2004). 
En cuanto a este caso, se encontró que en 1990 el territorio de la comunidad mantenía $77 \%$ de cobertura forestal (2,373 ha), mientras que para el 2000 disminuyó $17 \%$, es decir, contaba con $60 \%$ de mancha boscosa (1,849 ha) (cuadro 2). Para hacer una comparación, Cortina et al. (2005: 60) muestran que los ejidos y comunidades de la región templada de Los Altos, que mantienen más de $20 \%$ de la tierra aún sin parcelar bajo propiedad común, todavía cuentan con una superficie forestal que supera $40 \%$, mientras que los ejidos y comunidades que parcelaron toda su superficie puede variar de 10 a $70 \%$ de superficie forestal. En relación con estos rangos de referencia, encontramos que $60 \%$ de esta superficie, que la comunidad mantiene en relación con el total de su territorio, todavía es un porcentaje alto.

Para hacer otra comparación, estudios recientes de Cayuela et al. (2006b: 212) estimaron una tasa de 4.8\% de deforestación anual entre 1990 y 2000 para la región de Los Altos. Esta magnitud de deforestación se encuentra alejada del cálculo de la comunidad, que en 10 años disminuyó 17\%. D ebe quedar claro que la disminución de bosque en esta comunidad se ha dado principalmente en la zona sur (parte inferior de las imágenes en la figura ॥). Precisamente estas zonas son de menor altitud, donde el bosque predominante es de encino y demás árboles de hoja ancha.

La superficie de bosque ubicada en la parte superior de las imágenes es de mayor altitud y se caracteriza por especies de coníferas, especies que precisamente tienen un mayor valor en el mercado de la madera. Los claros que aparecen en la parte superior de las imágenes en 1990, para el año 2000 gran parte de ellos aparecen cerrados. Estas zonas son sobre todo bosque de coníferas y es donde los comuneros realizan la extracción de madera, las reforestaciones anuales y las faenas colectivas. Si la comunidad atiende más las áreas de bosque de coníferas es porque de allí obtienen beneficios económicos importantes. Así, la provisión y cuidados forestales en la comunidad dependen altamente del valor económico de los productos obtenidos.

Es importante señalar que la comunidad y su PSP perciben como muy extensas las áreas de encino, al grado que creen muy difícil que se agote. El apoyo técnico de los asesores forestales proyecta que en el futuro las especies de pino extiendan su superficie, pues cada año se siembran un poco más de diez mil plántulas, y la mayoría es para las áreas donde se extrajo madera.

Aunque localmente se tiene una percepción de abundancia en áreas de encino, los resultados de este estudio indican una dismi- 


\section{Figura II}

\section{Cambios en la superficie forestal en el área de la comunidad}

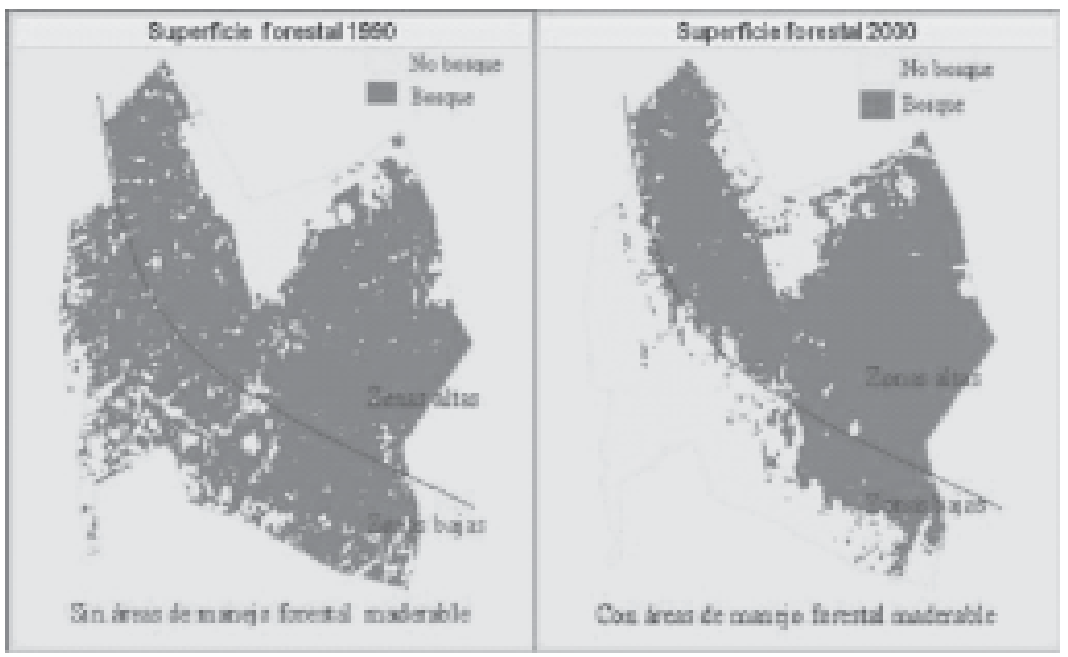

Fuente: Elaboración propia.

nución gradual, lo que en el futuro puede llevar a su desaparición. Es importante recordar que $95 \%$ de la comunidad consume leña de encino para uso doméstico, por lo que debiera representar un recurso indispensable para el futuro, aunque no se descarta el posible cambio de tecnologías para el consumo de combustible doméstico, como el uso de estufas ahorradoras de leña.

Si bien en estas áreas de encino se tiene exclusividad en el acceso, se ha determinado la cantidad para uso familiar por comunero, se prohíbe la venta de leña, se vigila y se aplican sanciones para quien no respete lo acordado. ¿Q ué sería de esta área de bosque si no existieran estos arreglos comunitarios?

\section{Conclusiones}

Con lo abordado hasta aquí, se puede considerar que existe suficiente información para atender las preguntas que se plantean al principio de este estudio. Trataremos, pues, de concluir con sus respuestas.

¿La comunidad cuenta con instituciones de acción colectiva para controlar sus recursos forestales? Este estudio demuestra que la Comunidad Agraria Teopisca tiene un complejo de reglas y acuerdos que permiten controlar colectivamente no sólo quién tiene acceso al recurso, sino la cantidad del mismo, la forma y 
tiempos para extraer los beneficios y para dotarlo de cuidados y mantenimiento. Asimismo, cuenta con mecanismos de supervisión para evitar que quienes no tienen derecho al recurso forestal lo invadan, y también de modos de vigilancia para que las reglas se cumplan internamente. Cuando no se cumplen, la comunidad tiene diversas sanciones que dependen de la gravedad de la falta cometida. Cabe identificar que, aunque se tiene control sobre el uso de leña, las reglas sobre el bosque de coníferas son más duras y exigentes que para el resto de las especies arboladas, pues el valor de éstas es mayor en el mercado.

Los comuneros demuestran un desarrollo en su organización basado sobre todo en la política interna de que las oportunidades en general, los derechos y beneficios del bosque sean distribuidos igualitariamente, y con ello poder asumir que las responsabilidades y las obligaciones también las ejerzan por igual todos los comuneros. En este sentido, no caben las propuestas de desarrollo fomentadas desde el exterior, que son diseñadas con repartos de poder, de ingresos económicos y de responsabilidades desiguales.

¿Cómo es el desempeño de tales instituciones? Los comuneros comenzaron en 1969 un proceso de gestión local en favor de la lucha por la tierra, hace casi 40 años. Las instituciones de esta comunidad son muy jóvenes en relación con comunidades que llevan cien años, o tan antiguas como las que surgieron hace cientos de años y aún persisten (Ruc de larga duración, O strom, 1990). En esas comunidades antiguas se desarrollaron instituciones que se han ido transformando de acuerdo con las presiones de los tiempos cambiantes. Este estudio deja ver un caso donde es posible desarrollar instituciones de acción colectiva para administrar los bosques de uso común en relativamente muy pocos años.

¿Q ué sucesos históricos contribuyeron a su desarrollo? El enfoque institucional de Elinor Ostrom (1990) es muy útil para identificar y describir las condiciones de las instituciones de acción colectiva en la comunidad, pero cabe enfatizar que profundizar en las experiencias significativas como la lucha por poseer la tierra, las primeras labores de reforestación y cuidados al bosque y las primeras comercializaciones de madera forman parte de un proceso de apropiación del territorio. El análisis de este proceso permite identificar las bases de la organización comunitaria, es decir, aquello que orientó el desarrollo de tales instituciones. El fortalecimiento de la acción colectiva es lo que con el tiempo logra hacer más eficiente el proceso de gestión local. Con 
ello, la comunidad mantiene una visión compartida sobre sus intereses en relación con sus recursos forestales. En este sentido, las reglas diseñadas por los comuneros mismos son más reconocidas, más vigiladas y sancionadas en su cumplimiento a partir de que se elaboran, entienden y justician localmente.

¿Cómo han influido los actores externos en las acciones de la comunidad sobre el recurso? La influencia directa de los agentes externos ha favorecido en gran medida el fortalecimiento de las capacidades locales para desarrollar instituciones de acción colectiva sobre sus recursos forestales. Aunque se debe aclarar que estas capacidades se han enfocado a un solo producto del bosque: el maderable, por su importante valor de mercado, dejando de lado los servicios ambientales que los bosques más conservados ofrecen. Con esto se está orientando a valorar las áreas de bosque más por los ingresos económicos que genera, que por la biodiversidad y los servicios ecológicos que puede ofrecer.

$\mathrm{H}$ asta el momento en que se elaboró este estudio, los planes de manejo forestal que el gobierno requería para autorizar permisos de extracción de madera no promovían la participación conjunta de la comunidad. M ás que una planeación de manejo forestal comunitario, el gobierno requería un estudio técnico de extracción y provisión del recurso (conocido como plan o programa de manejo). Para lograr un manejo forestal que integre las oportunidades y mejoras que requiere el sector forestal, es necesario usar métodos de planeación que involucren la participación comunitaria. Si esto conduce a una autonomía en la gestión local de los recursos naturales, se pueden garantizar mayores efectos de desarrollo económico, de autogestión comunitaria y de disponibilidad del recurso a largo plazo.

¿Existe alguna relación entre la gestión local de la comunidad con el estado actual del recurso? La cobertura que ocupa el recurso forestal de la comunidad ha disminuido, al igual que la mayoría de las comunidades y ejidos de la región y del estado de Chiapas, pero su tasa de deforestación es mucho menor en relación con la que se ha estimado en el ámbito regional. Ante esto, se reconoce que el complejo de reglas y acuerdos que la comunidad ejerce sobre sus bosques, su sistema de vigilancia y sobre la aplicación de sanciones han sido un factor muy importante para detener la presión hacia los recursos forestales.

El desarrollo de instituciones locales que fomenten la protección de los bosques dependerá también de la percepción de la abundancia o escasez de los productos que ofrece. Asimismo tendrá que ver 
con el valor social que se le dé o de lo que ha costado mantenerlo colectivamente. Además, la continuidad y funcionamiento del sistema de reglas dependerá mucho de la valoración económica que proporcione a sus poseedores. Esto será determinante para que permanezca 0 aumente su superficie forestal y que ésta pueda proveer ingresos económicos a lo largo del tiempo. Cuando el bosque no da beneficios económicos importantes a la comunidad, las decisiones de sus dueños se pueden orientar hacia el cambio de uso de suelo o a que predomine una especie comercial.

\section{Bibliografía}

Agrawal, Arun (2005), “Environmentality: Community, Intimate Government, and the M aking of Environmental Subjects in Kumaon, India", Current Anthropology, 46 (2), University of Chicago Press, Chicago, pp. 161-190.

Alcorn, Janis y Víctor Toledo (1998), "Property rights shells and ecological sustanibility: ejidos and resilient resourse management in M exico's forest ecosystem", en F. Berkes y C. Folke (eds.), Linking Social and Ecological Systems, Cambridge University Press, Cambridge, pp. 216-249.

Angelsen, Arild y David Kaimowitz (1999), "Rethinking causes of deforestation: lessons from economic models", World Bank Research O bserver, 14, Banco M undial, pp. 73-98.

Bello, Eduardo (2001), “M ilpa y madera, la organización de la producción entre mayas de Q uintana Roo", tesis doctoral, Universidad Iberoamericana, M éxico.

Bonfil, Silvia (2002), "N egociando el interés común”, Relaciones, XXIII (89), El Colegio de M ichoacán, M éxico, pp. 127-156.

Bray, David y Leticia M erino (2004), La experiencia de las comunidades forestales en México. Veinticinco años de silvicultura y construcción de empresas forestal es comunitarias, INESemarnat-Consejo Civil M exicano para la Silvicultura Sostenible, A.C., M éxico.

Bray, David, Leticia M erino, Patricia N egreros-Castillo, Gerardo Segura-Warnholtz, Juan M anuel Torres-Rojo y Henricus 
Vester (2003), “M exico's community-managed forests as a global model for sustainable landscapes", Conservation Biology, 17 (3), Department of Environmental Studies, Florida International University, M iami, pp. 672-677.

Bray, David, Camille Antinori y J uan M anuel Torres-Rojo (2006), "The M exican model of community forest management: The role of agrarian policy, forest policy and the empreprenurial organization", Forest Policy and Economics, 8, Elsevier B.V., St. Louis, M O, EUA, pp. 479-484.

Berkes, Fikret (1987), "Common Property Resource M anagement and Cree Indian Fisheries in Subartic Canada", en B. M cCay y J. Acheston (eds.), The Question of Commons. The Culture and Ecology of Communal Resources, University of Arizona Press, Tucson, pp. 66-91.

Bromley, Daniel W., D avid Feeny, M argaret A. M cKean, Pauline Peters, Jere Gilles, Ronald $O$ akerson, Ford Runge y James Thomson (eds.) (1992), Making the commons work: theory, practice, and policy, Institute for Contemporary Studies Press, San Francisco.

Cayuela, Luis, Duncan J. Golicher, Javier Salas y J ose M aría ReyBenayas (2006), "Classification of a complex landscape using Dempster-Shafer theory of evidence", International Journal of Remote Sensing, 27 (10), Taylor and Francis, Oxford, Reino Unido, pp.1951-1971.

Cayuela, Luis, José M aría Rey-Benayas y Cristian Echeverría (2006), "Clearance and fragmentation of tropical montane forests in the $\mathrm{H}$ ighlands of Chiapas", M exico (1975-2000), Forest Ecology and Management, Elsevier, París, pp. 208218.

Coespo (2000), Consejo Estatal de población del estado de Chiapas, Índices de Marginación.

Cortina, H éctor, Arturo Pizano, Duncan Golicher y M iguel Ángel Vázquez (2005), "Factores que influyen en el mantenimiento de áreas forestales bajo propiedad social en LoS Altos de C hiapas, M éxico", en Austreberta N azar, Eduar- 
do Bello y H elda M orales (eds.), Sociedad y entorno en la frontera sur. Grupos humanos, ambiente y políticas públicas, Red de Estudios Poblacionales en la Frontera Sur-EI Colegio de la Frontera Sur, M éxico, pp. 45-64.

Chambille, Karel (1983), Atenquique: los bosques del sur de Jalisco, Instituto de Investigaciones Económicas-Universidad $\mathrm{N}$ acional Autónoma de $\mathrm{M}$ éxico, $\mathrm{M}$ éxico.

Chapela, Francisco (1999), Silvicultura comunitaria en la sierra de O axaca. M éxico, Red de Gestión de Recursos N aturales-Fundación Rockefeller, M éxico.

Chuvieco, Emilio (2002), Teledetección ambiental. La observación de la Tierra desde el espacio, Ariel, Barcelona.

Fenny, David, Fikret Berkes, Bonnie J. M cCay y James Acheson (1990), "The Tragedy of Commons: Twenty-Two Years Later", H uman Ecology, 18 (1), Springer Science y Business M edia, N ueva York, pp. 1-19.

Garibay, Claudio (2002), "Comunidades antípodas", Relaciones, xxIII (89), El Colegio de M ichoacán, M éxico, pp. 83-125.

Gibson, Clark, Elinor O strom y M argaret M cKean (2000), "Forests, People, and Governance: Some initial theoretical lessons", en Clark Gibson, M argaret McKean y Elinor O strom (eds.), People and Forests. Communities, Institutions, and Governance, MIT Press, Cambridge, M assachusetts, pp. 227-242.

González-Espinosa, M ario, Susana O choa-Gaona, N eftalí Ramírez-M arcial y Pedro Q uintana-Ascencio (1997), “Contexto vegetacional y florístico de la agricultura", en $M$. Parra y B. Díaz (eds.) Los Altos de Chiapas: agricultura y crisis rural: Ios recursos naturales, El Colegio de la Frontera Sur, M éxico, pp. 86-117.

Gürerk, Ö zgür, Bernd Irlenbusch y Bettina Rockenbach (2006), "T he Competitive Advantage of Sanctioning Institutions", Science, 312 (5770), Asociación Americana para el Avance de la Ciencia (AAA), N ueva York, pp. 108-111. 
$\mathrm{H}$ ardin, Garret (1968), "The tragedy of the commons", Science, 162 (3859), Asociación Americana para el Avance de la Ciencia (AAA) N ueva York, pp. 1243-1248.

IBDR (International Bank for Reconstruction and Development) (1995), Mexico-Community Forestry. Technical Report, PID MXPA 7700, IBDR, Washington.

INEGI (Instituto N acional de Estadística, Geografía e Informática) (1993), Resultados definitivos, VII Censo Ejidal, INEGI, M éxico.

INEGI (Instituto N acional de Estadística, Geografía e Informática) (2000), XII Censo de Población y Vivienda 2000, INEGI, M éxico.

Klooster, Daniel (2002), "Towards Adaptive Community Forest $M$ anagement: Integrating Local Forest Knowledge With Scientific Forestry", Economic G eography, 78 (1), Clark University, Worcester, M A., p. 43.

Lin, N an (2001), Social Capital: A Theory of Social Structure and Action, Cambridge University Press, N ueva York.

Linck, Thierry (2006), De la globalización al territorio. La economía y la política en la apropiación de los territorios, IN RA, París.

M árquez, Conrado (2005), "Apropiación del territorio y gestión de los recursos forestales. Estudio de caso en ejidos de M arqués de Comillas, Selva Lacandona, Chiapas", en M .C. del Valle Rivera, E. Boege Schmidt y R. García Zamora (coords.), Los actores sociales frente al desarrollo rural: manejo de los recursos naturales y tecnológicos en el marco de la globalización, tomo I, Asociación M exicana de Estudios Rurales, M éxico, pp. 111-141.

M cKean, M argaret A. (2002), "Common Property: W hat is It, What is it Good For, and What M akes it Work?", en $M$ argaret $A$. M cKean, Clark Gibson y Elinor Ostrom (eds.), People and Forests: Communities, Institutions, and Governance, The m IT Press, Cambridge, pp. 27-55. 
M erino, Leticia y Gerardo Segura (2002), “EI manejo de los recursos forestales en M éxico (1992-2002). Procesos, tendencias y políticas públicas", en E. Leff, I. Pisanty y P. Romero (comp.), La transición hacia el desarrollo sustentable. Perspectivas de América Latina y el Caribe, PNum A, M éxico, pp. 237-256.

M erino, Leticia (2004), Conservación o deterioro. El impacto de las políticas públicas en las instituciones comunitarias y en las prácticas de uso de los recursos forestales, INE-Semarnat-ccm Ss, M éxico.

M orán, Emilio, Elinor O strom y J. C. Randolph (1998), A multilevel approach to studying global environmental change in forest ecosystem, Indiana University-CIPEC, Bloomington.

N etting, Robert M. (1993), Smallholders, H ouseholders: Farm Families and the Ecology of Intensive, Sustainable Agriculture, Stanford University Press, Stanford.

OIson, M ancur (1965), The Logic of Collective Action, H arvard University Press, Cambridge.

O strom, Elinor (1990), Governing the Commons: The evolution of Institutions for Collective Action, C ambridge University Press, Nueva York.

O strom, Elinor (1995), "Property Rights and the Environment", en S. H anna y M. M unasinghe (eds.), Social and E cological Issues, The Beijer Internation Institute-The World Bank, Washington.

Parra, M anuel (1989), El subdesarrollo agrícola en la subregión Altos de Chiapas, cies-Universidad Autónoma Chapingo, M éxico.

Pizano, A rturo (2002), "Factores que influyen en el mantenimiento de áreas forestales bajo propiedad social en Los Altos de Chiapas, M éxico", tesis de maestría, El Colegio de la Frontera Sur, M éxico. 
SARH (Secretaría de Agricultura y Recursos H idráulicos) (1994), Inventario forestal periódico del estado de Chiapas, SARH, M éxico.

Semarnap (Secretaría de M edio Ambiente, Recursos $\mathrm{N}$ aturales y Pesca) (1998), Anuario estadístico de la producción forestal, Semarnap, M éxico.

Tejeda-Cruz, Carlos (2005), “Apropiación social del territorio y política ambiental en la Selva Lacandona, C hiapas. El caso de Frontera Corozal, Comunidad Lacandona", en M aría del Carmen del Valle Rivera y Eckart Boege (coords.), Los actores sociales frente al desarrollo rural: manejo de los recursos naturales y tecnológicos en el marco de la globalización, tomo I, Asociación M exicana de Estudios Rurales, M éxico, pp. 143-171.

Torres-Rojo, J uan M anuel (2005), "Prediction of multimodal diameter distributions through mixtures of weibull distributions", Agrociencia 39 (2), El Colegio de Postgraduados, M éxico, pp. 211-220.

Villafuerte-Solís, Daniel, M aría del Carmen García y Salvador M eza (1997), La cuestión ganadera y la deforestación: viejos y nuevos problemas en el trópico y Chiapas, Universidad de Ciencias y Artes del Estado de Chiapas-Centro de Estudios Superiores de M éxico-Centroamérica, Tuxtla Gutiérrez, Chiapas.

Weber, Jacques y Jean Pierre Reveret (1993), Biens communs: les leurres de la privatisation. En Une terre en renaissance, ORSTOM-Le M onde Diplomatique, París.

Recibido: 18 de junio de 2008. Aceptado: 5 de enero de 2009.

Alma Rafaela Bojórquez Vargas. Es maestra en ciencias en recursos naturales y desarrollo rural por El Colegio de la Frontera Sur; licenciada en administración pública por la Universidad de O ccidente, en Sinaloa. Actualmente trabaja como profesora-in- 
vestigadora en la Universidad Autónoma de San Luis Potosí, en la carrera de turismo sustentable. Su línea de investigación se orienta a la gestión de comunidades rurales con potencial turístico.

Eduardo Bello Baltazar. Es doctor en antropología social por la Universidad Iberoamericana; maestro en ciencias agrícolas por el Colegio de Postgraduados; ingeniero agrónomo por la Universidad Autónoma M etropolitana. Es investigador de EI Colegio de la Frontera Sur, Unidad San Cristóbal de Las Casas, donde estudia las implicaciones sociales del manejo de los recursos naturales en temas como: organización social y territorio, comunidad y planes de manejo del bosque (ecoturismo, silvicultura, productos no mayas de Quintana Roo, economía y territorio maderables), ritualidad y redes sociales, leyes y normas locales. Dos de sus publicaciones recientes son: en coautoría, "M ayas de Quintana R 0o, M éxico: economía y territorio", en Luis Eugenio di $M$ arco (ed.), América Latina y la construcción del humanismo económico, Centro de Investigaciones Económicas de Córdoba, Argentina, pp. 93-97 (2006); en coautoría, "Religiosidad maya en Quintana Roo: redes sociales y políticas", en Elizabeth Díaz Brenis y E. M asferrer Kan (eds.), Valores religiosos y derechos humanos, xx Congreso de Religión, Sociedad y Política. Las iglesias en los procesos el ectorales, Q uerétaro, M éxico, p. 14 (2006).

Conrado M árquez Rosano. Es doctor en estudios rurales por la Universidad De Toulouse Le M irail, Francia; maestro en ciencias del desarrollo rural regional por la Universidad Autónoma Chapingo, universidad donde estudió para ingeniero agrónomo fitotecnista. Desde 1983, trabaja como docente e investigador en la Universidad Autónoma Chapingo; actualmente se encuentra en el Centro Regional Universitario del Anáhuac (CRUAN). Su actual línea de investigación aborda los temas: apropiación del territorio y gestión de recursos forestales. Su publicación más reciente es "¿Q ué significa un manejo culturalmente aceptable de los recursos naturales? Una reflexión desde la experiencia de trabajo en la Selva Lacandona", en Tim Trench y Artemio Cruz León (coords.), La dimensión cultural en procesos de desarrollo rural regional: casos del campo mexicano, Universidad Autónoma Chapingo, M éxico, pp. 128-184 (2008).

Luis Cayuela. Es doctor por la Universidad de Alcalá; realizó sus estudios de licenciatura en la Universidad Autónoma de M adrid y de maestría en la University College of London. Actualmente 
es investigador posdoctoral en la Universidad de Granada. Entre sus líneas de investigación destaca el estudio de los patrones de diversidad vegetal a distintas escalas espaciales, la deforestación y la ecología forestal, con especial énfasis en la investigación aplicada a la gestión forestal. Durante muchos años ha participado en proyectos internacionales en Latinoamérica, sobre todo en $M$ éxico, Costa Rica y Chile. En la actualidad su trabajo se centra en la investigación aplicada al manejo de recursos forestales en bosques mediterráneos de Andalucía. Entre sus publicaciones más recientes destacan: en coautoría, "Early environments drive diversity and floristic composition in M editerranean old fields: Insights from a long-term experiment", Acta O ecologica, 34 (3), Elsevier, París, en coautoría "Applying Climatically Associated Species Pools to modelling compositional change in tropical montane forests", Global Ecology and Biogeography, 17(2), Elsevier, Paris, pp. 262-273 (2008).

M anuel Roberto Parra Vázquez. Es doctor en economía por la Universidad Nacional Autónoma de M éxico; maestro en ciencias agrícolas por el Colegio de Postgraduados de Chapingo e ingeniero agrónomo zootecnista por la Escuela N acional de Agricultura. $\mathrm{H}$ a sido profesor e investigador de la Universidad Autónoma Chapingo, el Colegio de Postgraduados de Chapingo y El Colegio de la Frontera Sur, donde coordina investigaciones sobre desarrollo rural en áreas campesinas del centro y sureste de M éxico con un enfoque territorial y bajo una perspectiva interdisciplinaria. Actualmente estudia los procesos de diseño de políticas públicas para el desarrollo local. Su objetivo es propiciar, mediante un aprendizaje social, el establecimiento de sistemas de manejo sustentable de la tierra basados en los saberes de todos los participantes. Es reconocido por sus publicaciones sobre la agricultura en Los Altos de Chiapas. Una de sus obras destacadas es, en coautoría, Los Altos de Chiapas: agricultura y crisis rural, tomo 1, Los recursos naturales, Ecosur-Semarnap, San Cristóbal de las Casas, Chis. (1997). 